RESEARCH PAPER RP1611

\author{
Part of Journal of Research of the National Bureau of Standards, Volume 33, \\ October 1944
}

\title{
MACHINES AND METHODS FOR TESTING CORDAGE FIBERS
}

\author{
By Herbert F. Schiefer
}

\section{ABSTRACT}

Machines are described for testing the flexural endurance and the resistance to abrasion of cordage fibers. In the test for flexural endurance, a bundle of fibers having a twist of one turn per inch is repeatedly drawn back and forth over three small pulleys located at the vertices of an isosceles right triangle. In the test for resistance to abrasion, a similarly twisted bundle of fibers is drawn back and forth against a second bundle twisted once around the first. This test is made in such a way that the flexing of fibers during the test is reduced to a minimum.

The procedures for the selection of fibers, preparation of fiber bundles weighing 5 grains per 15 inches of length, and conditioning of test specimens are outlined. The unprocessed fibers were tested for the following: Fineness of fiber; dry and wet breaking strength and elongation; flexural endurance; resistance to abrasion; and the effect of elevated temperatures, continuous soaking in fresh and in salt water, alternate wetting and drying with fresh or salt water, and exposure to light with intermittent spraying with water. The results of tests of six lots of abaca, nine of sisal, two of jute, two of henequen, one of pita floja, one of ixtle, four of sansevieria, one of palmetto, three of hemp, two of roselle, one of manzanita, two of yucca, and one of malvita are given and discussed.

Great variations were found in the characteristics of different lots and grades of one kind of fiber. There was considerable overlapping in results of different kinds. No one kind of fiber was outstanding in all respects. Abaca was the strongest of the fibers tested, but some of the lots of abaca were weaker than some lots of sisal. Henequen and sisal were more resistant to abrasion than the other fibers tested, and they had higher flexural endurance, but were the least resistant to exposure to light and intermittent spraying with water. Pita floja, one of the strongest fibers tested, was one of the least resistant to abrasion. Sansevieria had exceptionally good strength. Hemp and jute were very similar in all of the characteristics measured. The resistance to abrasion of the fibers tested was profoundly affected by the direction of twist in the ply relative to that in the bundle, and also by the addition of a small amount of lubricant.

\section{CONTENTS}

I. Introduction

II. Testing procedures and equipment

1. Selection of fibers and preparation of fiber bundles

2. Fineness of fiber.

3. Twisting device

4. Breaking strength and elongation, dry _.

5. Breaking strength and elongation, wet

6. Flexural endurance

7. Resistance to abrasion

8. Accelerated weathering _._.

9. Resistance to elevated temperature

10. Resistance to continuous wetting with fresh or salt water..... 322

11. Resistance to alternate wetting and drying with fresh or salt water . . 
III. Materials tested

IV. Results

V. Discussion of results

1. Fineness of fiber

2. Breaking strength and elongation, dry and wet............ 330

3. Effect of soaking in water on breaking strength and elongation -332

4. Effect of temperature on breaking strength ............. 335

5. Effect of accelerated weathering on breaking strength $\ldots \ldots \ldots 336$

6. Relation of flexural endurance to dry breaking strength and elongation

7. Resistance to abrasion

(a). S-twist in the bundle and in the ply ............ 337

(b). S-twist in the bundle and Z-twist in the ply

VI. Conclusion .....

\section{INTRODUCTION}

The development of machines and procedures for testing cordage fibers was undertaken by the National Bureau of Standards at the request of the Board of Economic Wariare, which acted on the advice of a committee from the War Production Board, and the United States Departments of Agriculture, War, Navy, and Commerce. The funds for the investigation were in part provided by the Defense Supplies Corporation. The proposed study was discussed with experts of the cordage industry. In addition to the development of machines and testing procedures, the study included the testing of standard grades of cordage fibers as well as proposed substitutes.

The purpose of this investigation was to provide means for the quick evaluation of the characteristics of experimentally grown fibers and of less known native fibers. A further purpose was to provide data on the characteristics of fibers long used in the manufacture of rope and cordage as a basis for judging the suitability of other fibers. These methods and data can be employed in the search for and in the quick development of sources of substitute fibers, and obviate the need for large quantities of fiber to be made into rope for determining the suitability of the fiber by testing the rope. The results of the study should also aid in the improvement of cordage fibers after the war, since means are provided for measuring the characteristics of fibers from a single leaf and for conducting systematic and carefully planned experiments.

The machines and methods developed are suitable for testing processed or unprocessed fibers for the following: Breaking strength and elongation when dry and when wet; flexural endurance; resistance to abrasion; fineness of fiber; and effect of elevated temperatures, continuous soaking in fresh or salt water, alternate wetting and drying with fresh or salt water, and exposure to light with intermittent spraying with fresh water. The machines and methods predescribed in this paper, and the results of tests on a number of fibers, are reported.

Bundles of fibers, weighing 5 grains per 15 in. of length $(0.34 \mathrm{~g} / 40 \mathrm{~cm})$ and containing one turn of twist per inch of length were tested rather than individual fibers. This procedure was followed because the variation between individual fibers is so great as to make prohibitive the number of tests necessary for determining significant differences between kinds of fibers.

On the basis of the data presented, a number of fibers appear to be suitable as substitutes for abaca and sisal (hard) and jute (soft) fibers 
as far as their mechanical characteristics are concerned. The production facilities and cost of these fibers were not considered. One outstanding result of this investigation was the profound effect that the direction of twist in the ply relative to that in the bundle had on the resistance to abrasion of the fibers, regardless of the kind of fiber tested. The amount of twist in the bundle and in the ply also affect the resistance to abrasion. A systematic study of the influence of the amount of twist would yield worth-while information and indicate the optimum twist to be used for each fiber in the manufacture of cordage and rope having a high resistance to abrasion.

\section{TESTING PROCEDURES AND EQUIPMENT}

\section{SELECTION OF FIBERS AND PREPARATION OF FIBER BUNDLES}

Wisps of fibers were drawn at random from different parts of the fiber lot to be tested. The wisps were stroked by hand to remove tangled masses of short fibers. They were inserted in a template, and sections $15 \mathrm{in}$. in length were cut from the wisps. These sections were taken at random along the length to provide sampling of the various parts of a fiber from base to tip. Enough fibers of a lot were cut at one time to provide an ample supply for all the tests. The cut fibers were placed randomly in parallel alinement in a box to make the sample distribution of fiber as uniform as practicable. Individual fibers were drawn at random from this box to make a bundle weighing 5 grains. Whenever practicable, the fibers in each bundle were counted and recorded. In preparing a bundle, care was taken to aline the ends as evenly as practicable. Fibers shorter than $15 \mathrm{in}$. and those of irregular type, such as split or fractured fibers, were discarded. The above procedure was followed in preparing bundles of the different kinds of fibers, except that for such fibers as jute, pita floja, and hemp, the number of fibers in the bundles were not counted. For these fibers it was too difficult to ascertain what constituted a fiber without the aid of some magnifying device, and counting the number of fibers in each bundle was impracticable.

\section{FINENESS OF FIBER}

From the large number of bundles prepared from each fiber lot, the average number of fibers per 5-grain 15-in. bundle was calculated as well as the standard error of this average. This number is related to the fineness of fiber by the equation $F=1750 \mathrm{~N}$, where $F$ is fineness of fiber in feet per pound, and $N$ is the average number of fibers in a 5 -grain 15 -in. bundle.

For those fibers where it was impracticable to count the number in each bundle, a sample of the fibers 15 in. long was taken and weighed. The sample was then spread out in a fan-shaped pattern, and the number of fibers were counted with a widefield, low-magnification lens. A pair of sharp pick needles was found to be very helpful in separating the individual fibers while counting. Those fibers that separated very readily were considered as individual fibers, each fiber containing a group of elementary fiber cells. The number of fibers in a 5-grain 15-in. bundle was calculated from the number of fibers counted, usually more than 500 , and from their weight and 
length. The fineness of fiber was computed from the equation $F=1750 \mathrm{~N}$.

\section{TWISTING DEVICE}

The device for twisting the bundle of fibers is shown in figure 1 . The bundle was fastened at one end in a clamp that can be rotated with a crank. The other end was fastened in a clamp that is part of a compound pendulum pivoted at the bottom. The tension that the pendulum exerts on the fibers can be adjusted by changing the position of a weight. A tension of $75 \mathrm{~g}$ was found to be satisfactory. It remains essentially constant throughout the twisting operation and was used in the tests reported in this paper. The distance between the two clamps is $10 \mathrm{in}$. at the beginning of the twisting operation and slightly less at the end because of the lengthwise contraction of the bundle with twisting. The provision to permit contraction is essential in the twisting process. If it is lacking, the fibers may be damaged because a high tension is produced owing to the inherent low stretch of cordage fibers. A stop is provided to keep the pendulum and clamp in a fixed relation to the rotatable clamp while inserting the bundle.

\section{BREAKING STRENGTH AND ELONGATION, DRY}

The bundle of fibers was twisted one turn per inch of S-twist with the device described. The twisted bundle was removed from the twisting device and placed across a board 12 in. wide fitted with slotted leather strips along the two sides to hold the bundle taut and to prevent untwisting (fig. 2). In transferring the bundle, care was taken not to alter the twist. Two pairs of cardboard strips 1 in. wide and about one twenty-fifth inch thick were slipped under the bundles at $A, B, C$, and $E$ in figure 2 . These strips were made parallel to each other and were alined perpendicular to the length of the bundles. The distances between cardboards from $A$ to $B$ and from $C$ to $E$ are 3 in. The bundles were glued to the cardboards with carpenter's glue. The glue was allowed to dry and the fibers were conditioned for at least 12 hours in an atmosphere of 65 -percent relative humidity and $70^{\circ} \mathrm{F}$. The bundles were cut in the middle between cardboards $B$ and $C$, thus forming two test specimens of each bundle. The cardboard strips were then nearly cut through between the bundles (fig. 3), leaving about 1-in. squares of cardboard firmly attached to the ends of each half of the bundle of fibers. A specimen for test, readily detached from the remaining bundles by tearing the cardboard, was inserted in the flat clamps of a pendulum-type machine of 110-lb capacity. The speed of the pulling clamp was $12 \pm 0.5 \mathrm{in} . / \mathrm{min}$.

The cardboards and glue protected the fibers from being damaged when clamped in the machine and effectively eliminated slippage of fibers in the clamps. The small cardboard strips also were an aid in handling the bundles of fibers and in retaining the inserted twist. 


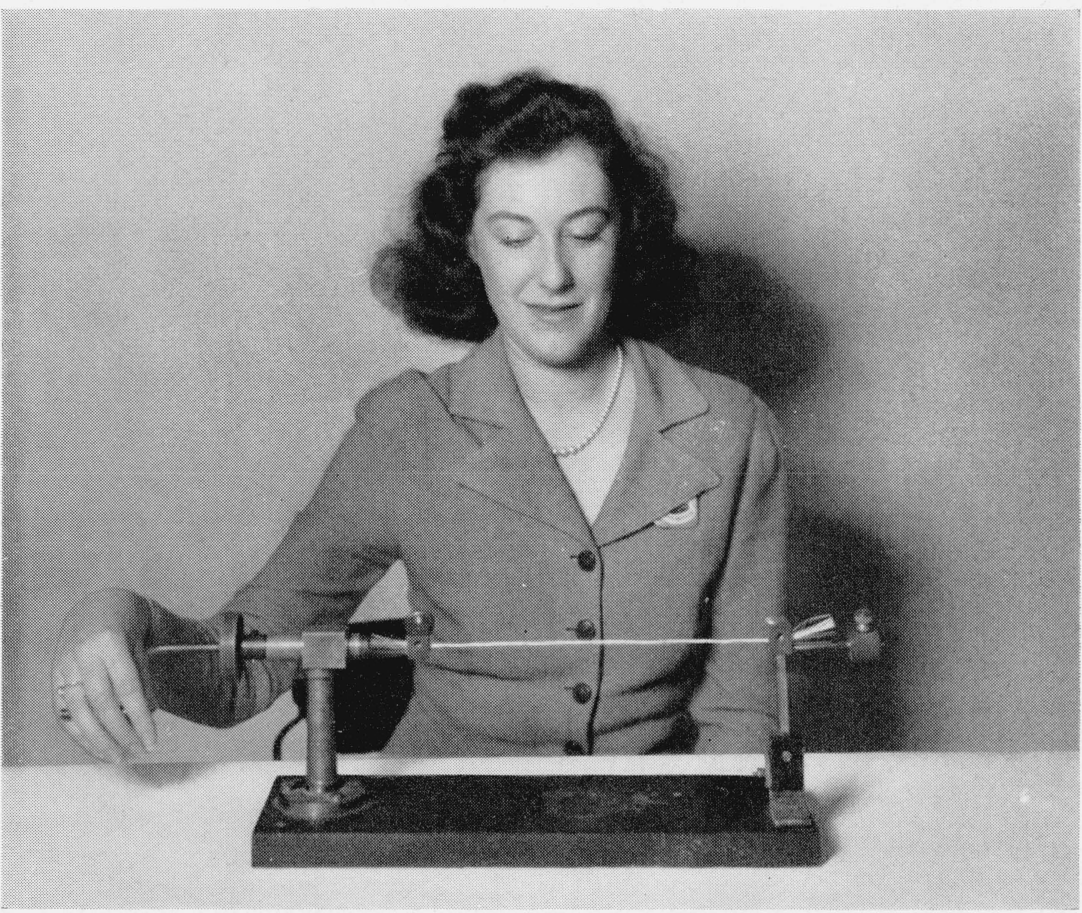

Figure 1.-Device for twisting a bundle of fibers. 


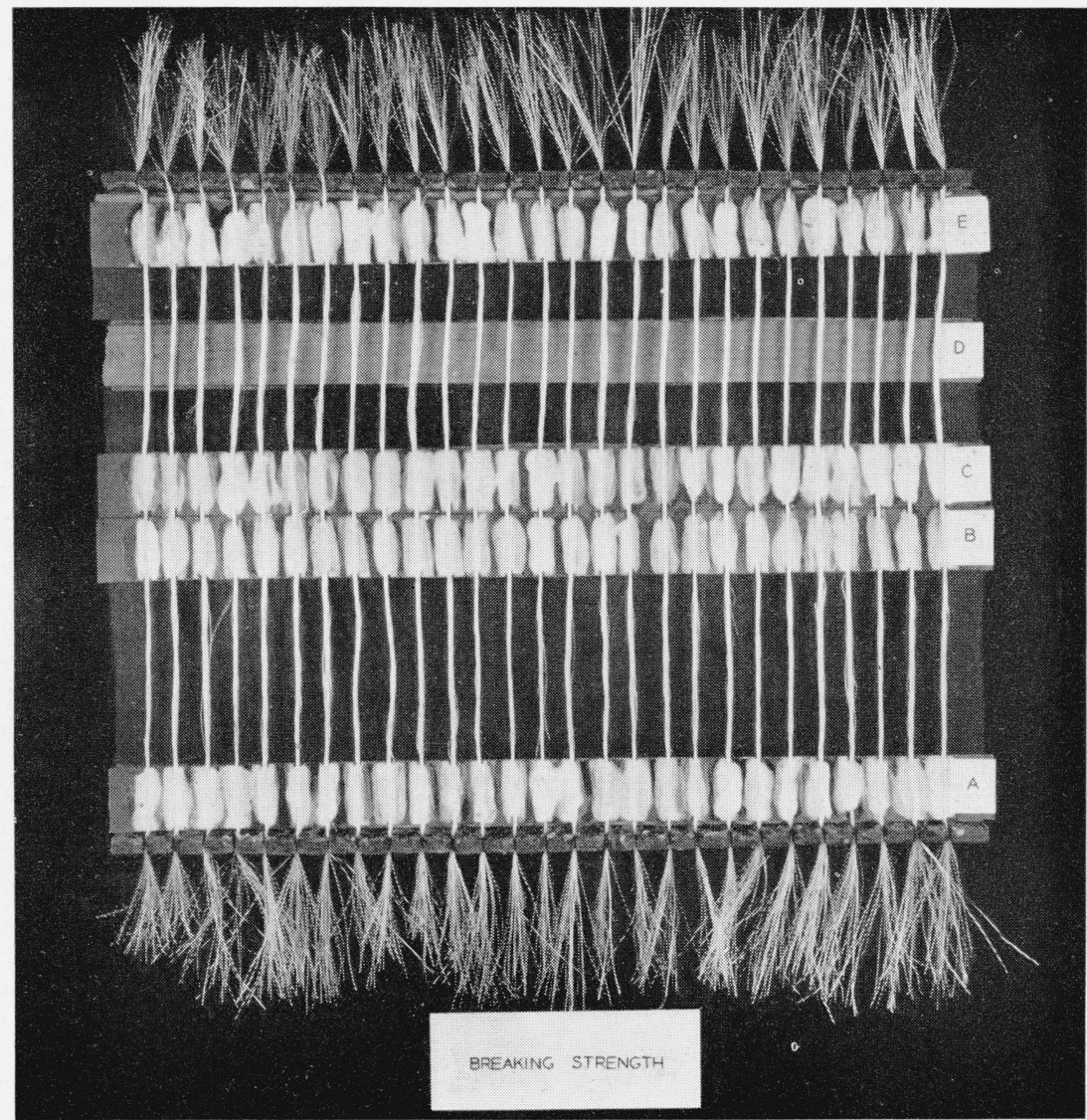

Figure 2.-Board for holding twisted bundles of fibers during gluing to strips of cardboard. 


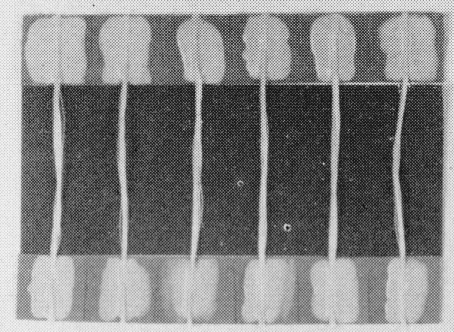

ORY BREAKING STRENOTH

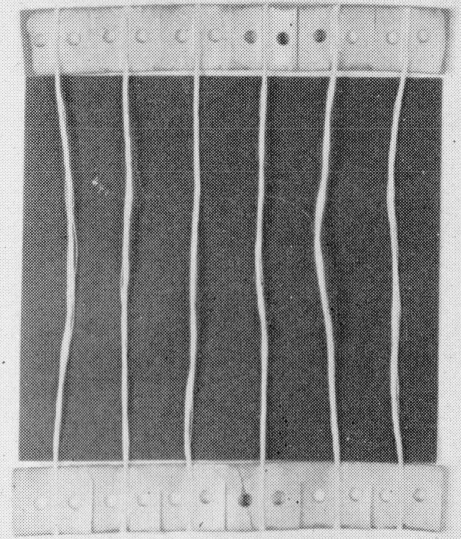

ABRASION

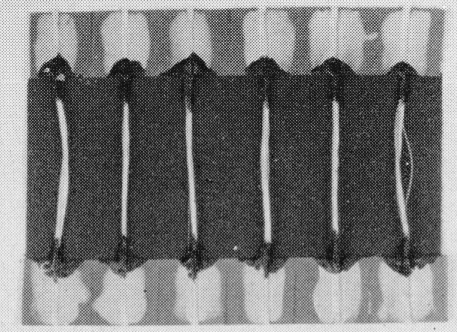

WET BREAKNC STRENGTH

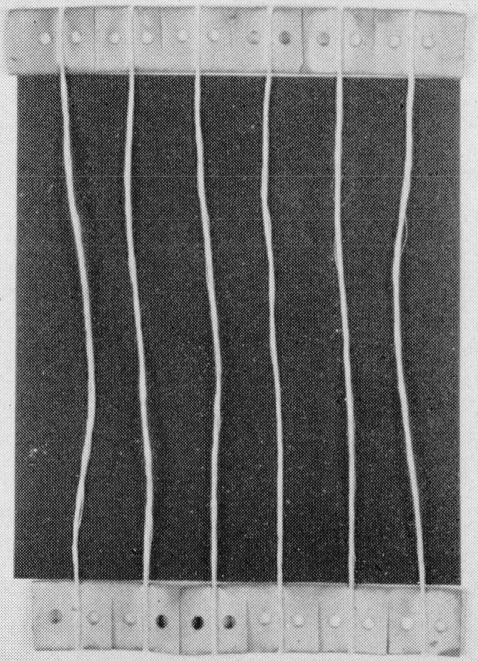

FLEXING

Figure 3.-Twisted bundles of fibers glued to cardboards for tests of dry and wet breaking strength, resistance to abrasion, and flexural endurance. 


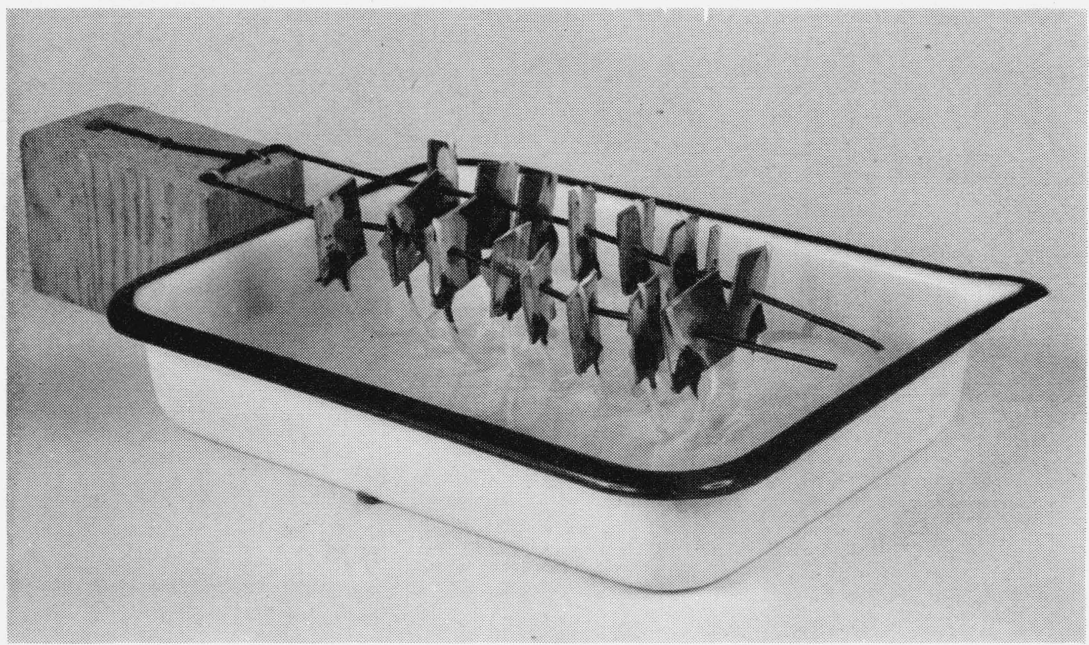

FIGURE 4.-Bundles of fibers partially immersed in water for tests of wet strength

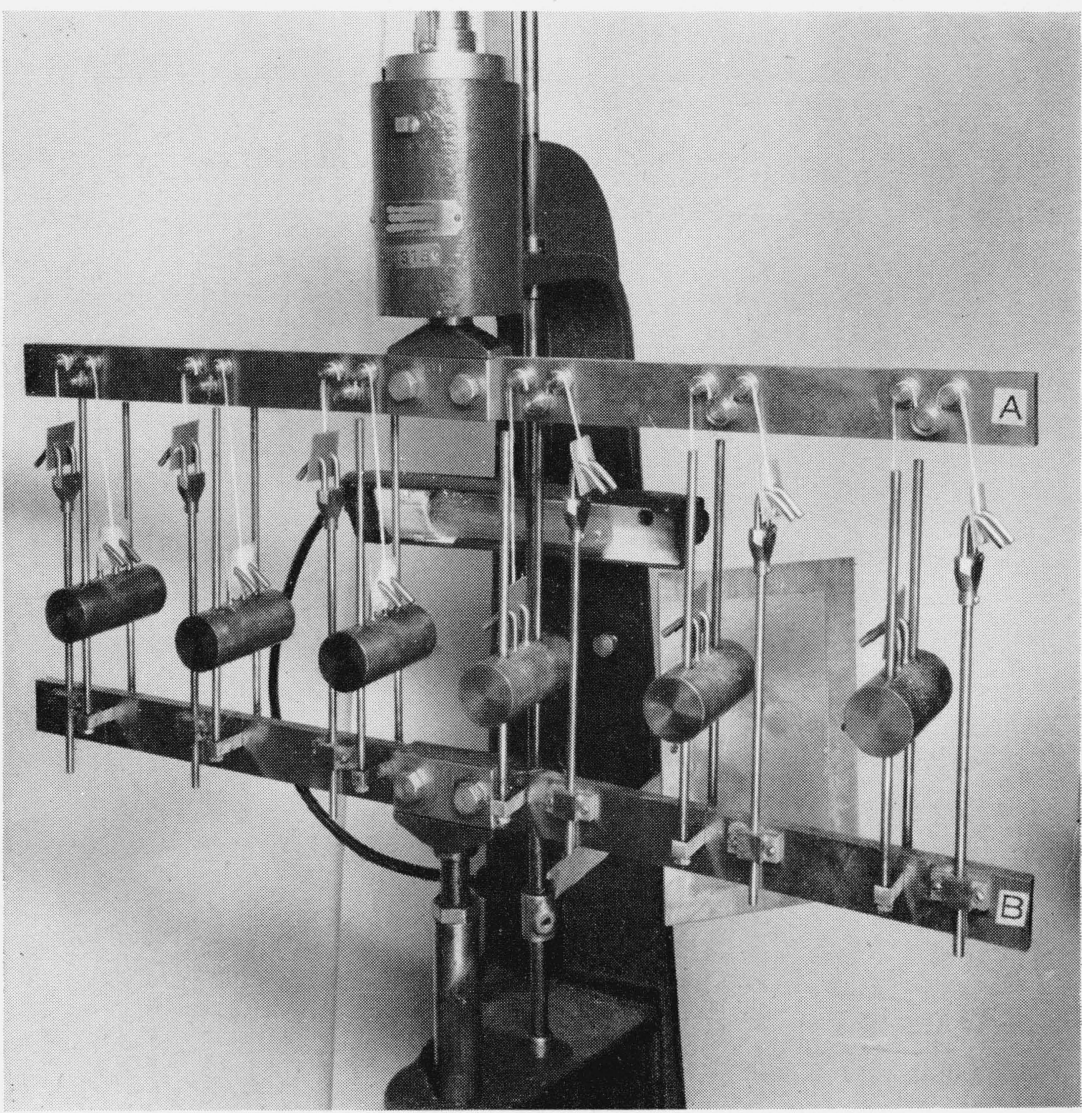

Figure 5.-Machine for testing the flexural endurance of bundles of fibers. 
The breaking strength and elongation were read from the scale and load-elongation curve. Fifty or more tests were usually made of each fiber lot. The average strength and elongation were calculated, as well as their standard errors. The breaking length of the bundle, that is, the length which would be just sufficient to break it under its own weight, was computed from the breaking strength and bundle weight and length, and is given by $L=1750 B$, where $L$ is breaking length in feet and $B$ is breaking strength in pounds.

\section{BREAKING STRENGTH AND ELONGATION, WET}

The bundles of fibers for tests of the wet strength were twisted, mounted on boards, and glued to strips of cardboard in the same manner as for tests of the dry strength. After the glue was dry a drop of hot ceresin was applied at the juncture of the fibers and the cardboard. This wax was applied with a hot copper tubing bent into the shape of a large pen. The wax is shown by a black discoloration of the bundles labeled "wet breaking strength" in figure 3. It effectively prevented the water from coming in contact with the cardboard and glue during soaking of the fibers. The bundles were cut in the middle as for tests of the dry strength, thereby forming two test specimens of each bundle. A hole, not shown in figure 3, was then punched in the cardboard at each end of the specimen. The cardboard was cut between the bundles as for the dry strength tests. Each bundle was then detached, formed into a $U$-shaped specimen, and strung on two long horizontal prongs through the punched holes (fig. 4). Care was taken to preserve the twist. The bundles were spaced far enough apart to avoid contact between them. This separation was essential to prevent water from rising between the fibers to the glue and cardboard. The bundles were placed over a flat dish containing water (fig. 4). The bottom of the U-shaped specimen was submerged about 1 in. into the water and allowed to soak overnight. One bundle at a time was then removed and immediately tested for wet breaking strength and elongation in the same manner as the dry bundles. The water that dripped from the fibers to the glued cardboard, which was fastened in the lower clamp, was in contact for such a short time that the cardboard and glue were not affected. The same number of tests and calculations were made as for the dry strength tests.

\section{FLEXURAL ENDURANCE}

The bundles of fibers for the flexural endurance tests were twisted one turn per inch of S-twist and then mounted on boards the same as for tests of the dry strength, except that they were spaced twice as far apart. They were glued to two strips of cardboard, the free length between the cardboards was 8 in. After the glue was dry, two holes were punched in the cardboard at the ends of each bundle, as illustrated in figure 3 for those labeled "flexing." The cardboard was cut between the bundles as was done in tests for strength. A bundle was then detached and tested with the machine shown in figure 5. 
Six twisted bundles of fibers are drawn back and forth simultaneously over three small pulleys $5 / 16$ in. in diameter located at the vertices of an isosceles right triangle, the hypotenuse being $7 / 8$ in. The ballbearing pulleys are attached to a fixed horizontal bar, $A$. A second horizontal bar, $B$, is attached to the shaft of a reciprocating mechanism, not shown, having a total stroke of 4 in. For each specimen the reciprocating bar contains a fixed rod with two prongs, to which the punched cardboard, glued to one end of the bundle of fibers, is attached. It also contains a pair of parallel rods which serve to guide the free up-and-down movement of a 1-lb weight. The weight contains two prongs, to which the punched cardboard glued to the other end of the bundle is attached. The twisted fibers are passed over the three pulleys as indicated in figure 5 . The twist is retained by the manner of attachment described, and tension is exerted by the weight during the back-and-forth movement of the fibers over the pulleys. A complete back-and-forth movement is called a flexing cycle. The machine operates at 60 cycles per minute. The number of cycles is recorded by a counter, which is not shown in the figure.

The six bundles of fibers mounted in the machine at a time were flexed for a preassigned number of cycles, after which their breaking strengths were determined. This procedure was repeated until a sufficient number had been tested to give a well-determined curve relating the breaking strength and number of flexing cycles. The number of cycles required to reduce the breaking strength to 50 percent of the dry breaking strength and to a breaking strength of $20 \mathrm{lb}$ were recorded from this curve.

\section{RESISTANCE TO ABRASION}

The bundles of fibers for the tests of the resistance to abrasion were twisted one turn per inch of S-twist and mounted on boards the same as for tests of the dry strength except that they were spaced twice as far apart. They were glued to two strips of cardboard, at $A$ and $D$ only (fig. 2). The free length between $A$ and $D$ was 6 in. After the glue was dry, two holes were punched in the cardboard at the ends of each bundle, as illustrated in figure 3 for those labeled "abrasion." The cardboard was cut between the bundles in the same manner as for tests for strength. The bundles were then detached and tested for resistance to abrasion with the machine shown in figure 6 . In this test a twisted bundle of fibers is drawn back and forth longitudinally against a second bundle that is twisted once around the first. Six pairs of bundles are tested simultaneously.

A motor speed reduction unit with a double-acting crankshaft imparts a reciprocating motion to two rods which move exactly out of phase. To each rod is attached a horizontal bar containing six pairs of prongs. The punched cardboard, glued to one end of a twisted bundle, is attached to a pair of prongs of one bar. The punched cardboard, glued to the other end of the bundle, is attached similarly to two prongs of a plate located directly below, and which is constrained to move in a guide inclined $4 \frac{11}{2}$ degrees to the vertical. 


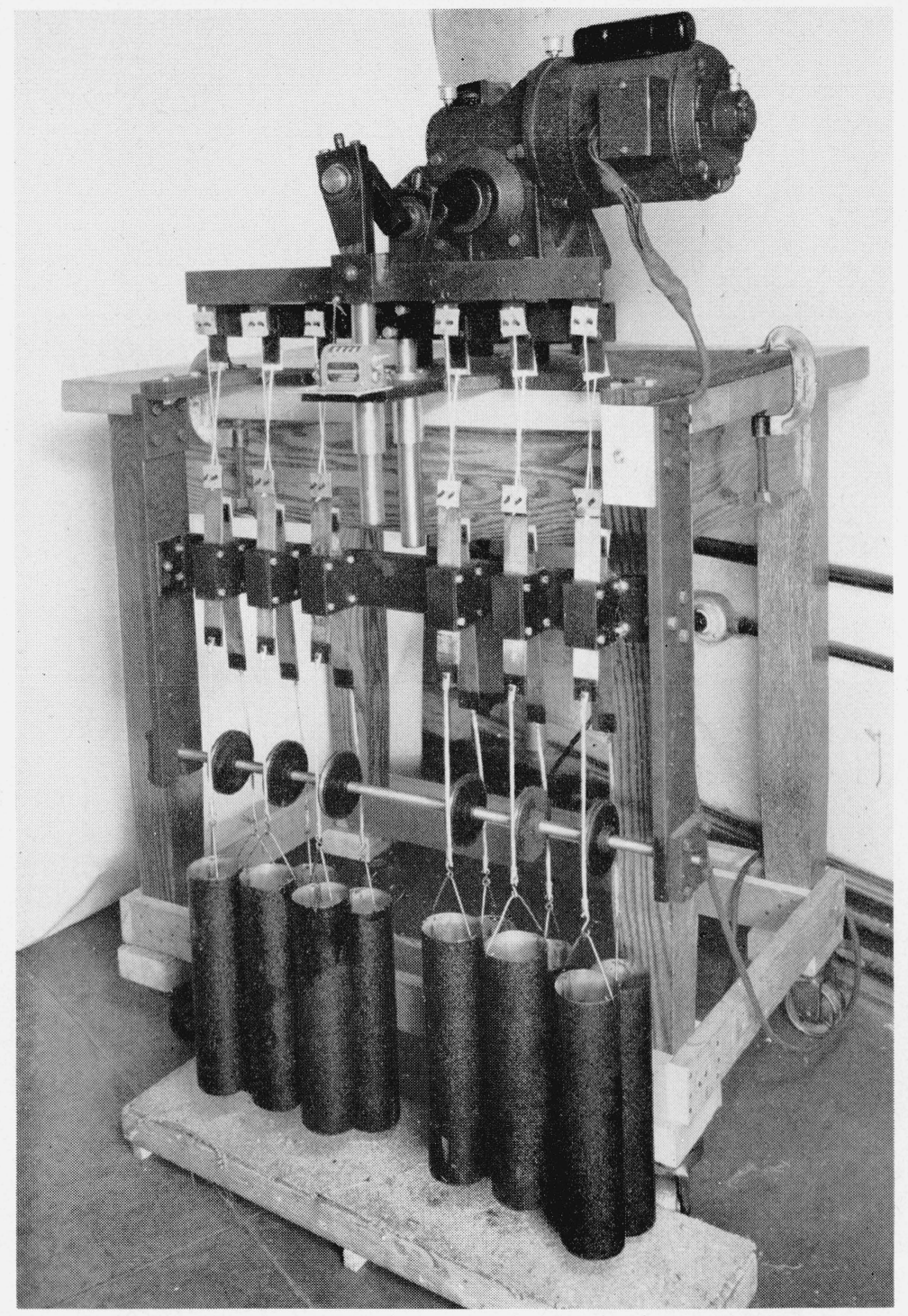

Figure 6.-Machine for testing the resistance to abrasion of bundles of fibers. 


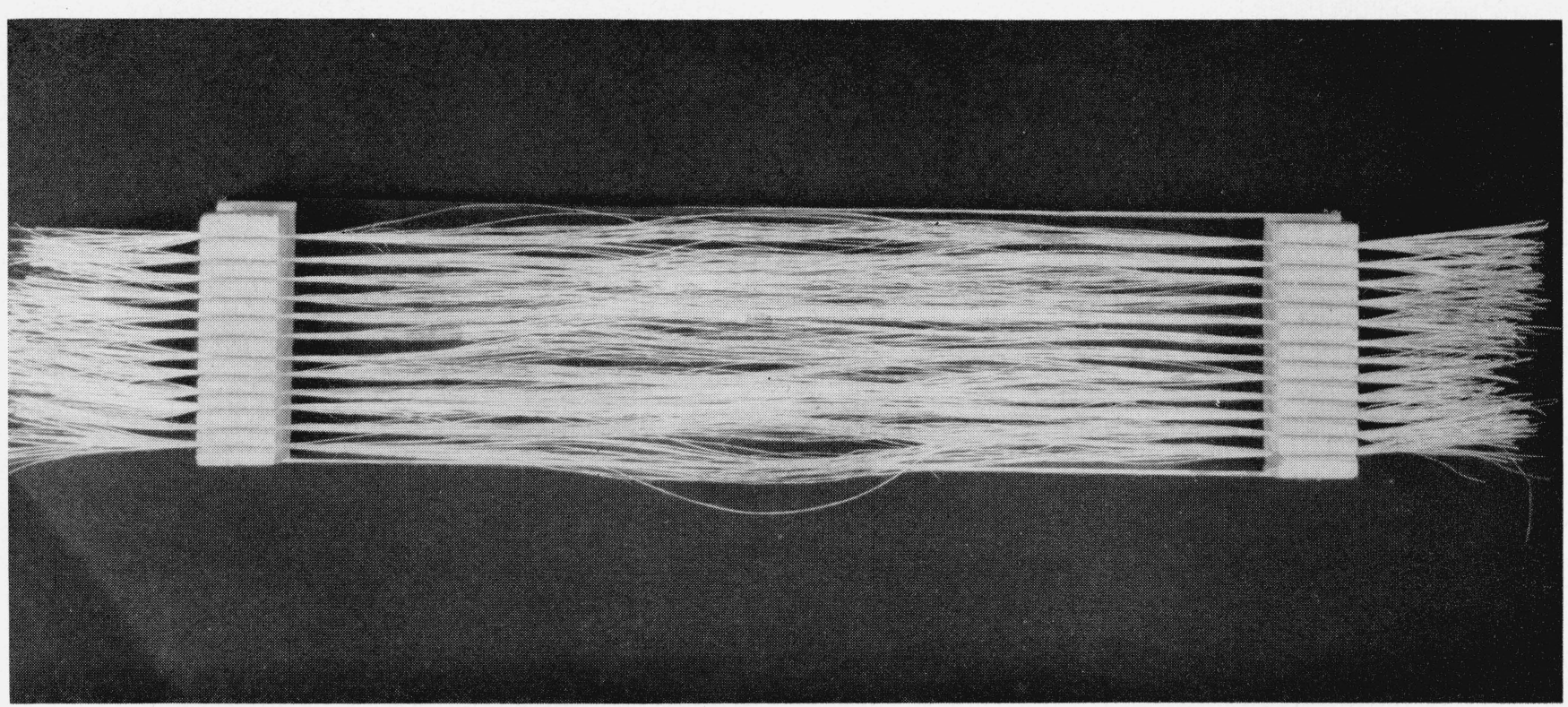

FIGURE 7.-Bundles of untwisted fibers mounted on a board for accelerated weathering in Weather-ometer. 
Similarly, the second bundle of a pair is attached to the second bar at the top and to a second plate at the bottom. The latter is also constrained to move in a guide inclined $4 \frac{1}{2}$ degrees to the vertical. 'The inclination of the two guide plates is toward each other, with an internal angle equal to 9 degrees. The S-twist of each bundle is preserved when mounting the bundles and while twisting the second bundle of each pair one turn of S-twist around the first.

A can containing lead shot is attached to the lower end of each plate by means of a metal cable. The motions of the metal cables are guided by ball-bearing idler pulleys to prevent the cans from touching each other. The total weight of each can is adjustable. A weight of $5 \mathrm{lb}$ was found to be satisfactory and was used for the fibers tested. The two bundles of a pair intersect with an angle of about 9 degrees, and this angle, as well as the twist, is essentially maintained during each complete back-and-forth movement, or cycle, of abrasion. The machine operates at 60 cycles per minute. The number of cycles is recorded by a counter located directly in front of the rods.

The six pairs of bundles tested at a time in the machine were abraded for a preassigned number of cycles, after which their breaking strengths were determined. This procedure was repeated until a sufficient number had been tested to give a well-determined curve relating the breaking strength and the number of cycles of abrasion. The number of cycles required to reduce the breaking strength to 50 percent of the dry breaking strength and to a breaking strength of $20 \mathrm{lb}$ were recorded from this curve.

The above procedure was repeated, except that the second bundle of each pair was twisted one turn of Z-twist around the first. A few tests were also made according to the above procedure but with a drop of lubricating oil added to each pair of bundles.

\section{ACCELERATED WEATHERING}

The accelerated weathering tests were made by exposing bundles of untwisted fibers to light, using the type DL-TS Weather-ometer. The essential features of this unit are two glass-enclosed carbon arcs, each are operating on 110-volt 60-cycle alternating current. The arc current is between 15 and 17 amperes. In each arc two carbons are used at the bottom and one at the top. Either a No. 20 cored carbon was used at the top and two No. 70 solid carbons were used at the bottom, or a No. 70 solid carbon was used at the top and two No. 20 cored carbons were used at the bottom. The samples were mounted on the inside of a cylindrical drum, which rotates around the arcs at 1 rpm. Thirty samples were exposed at a time. Each sample contains 12 bundles of fibers mounted on a special board, as shown in figure 7 . 
A vertical bank of four nozzles is provided for spraying the fibers with water. They rotate past this bank once each minute. The water spray is automatically turned on for a 3-minute period once every 20 minutes. A thermostat is provided to prevent the maximum temperature at the fibers from exceeding $140^{\circ} \mathrm{F}$. No provision is made for controlling the minimum temperature except by the water spray and temperature of the water. Provision is made for cooling the drum by a spray on the outside of the drum. A timing device records the number of hours of operation.

The bundles of fibers were exposed continuously to light and to intermittent spraying with water. At the end of a preassigned number of hours of exposure, a board containing 12 bundles of fibers was removed for each lot of fiber for tests of their strength. The exposure of the remaining boards of fibers was continued. They were likewise withdrawn for tests of their strength at the end of a preassigned number of hours of exposure.

The 12 bundles of exposed fibers from each board were removed, one at a time, twisted one turn per inch of S-twist, and mounted on a board and glued to four strips of cardboard in the same manner as for tests of dry strength, and two tests were made of each bundle. The average strength and standard error were calculated from the test results obtained for each exposure time of a fiber lot.

\section{RESISTANCE TO ELEVATED TEMPERATURE}

Thirty-six bundles of untwisted fibers from each lot of fiber to be tested were placed in an electric oven maintained at $105^{\circ}$ to $110^{\circ} \mathrm{C}$ $\left(221^{\circ}\right.$ to $\left.230^{\circ} \mathrm{F}\right)$. The air in the oven was circulated by a fan. Twelve bundles of fibers from each lot of fiber were removed from the oven at the end of 10,20, and 30 days exposure. The exposed fibers were then twisted one turn per inch of S-twist and mounted for tests of strength in the same manner as for dry strength, and two tests were made of each bundle. The average strength and standard error were calculated from the 24 test results obtained for each exposure time of a fiber lot.

\section{RESISTANCE TO CONTINUOUS WETTING WITH FRESH OR SALT WATER}

Fifty bundles of untwisted fibers from each lot of fiber to be tested were placed in a beaker containing tap water. The water was renewed each day. One half of the bundles were soaked for 12 days and the other half for 28 days. 
The soaked fibers were allowed to dry, after which they were twisted one turn per inch of S-twist, and mounted on boards for tests of strength in the same manner as for dry strength. Two tests were made of each bundle. The average strength and standard error and average elongation and standard error were calculated from the 50 test results obtained for each soaking time of a fiber lot.

The above procedure was repeated but water containing 3.7 percent of sea salt was used instead of tap water. The salt water was renewed each day.

\section{RESISTANCE TO ALTERNATE WETTING AND DRYING WITH FRESH OR SALT WATER}

Twenty-five bundles of untwisted fibers from each lot of fiber to be tested were placed in a beaker containing tap water. The bundles were removed after 24 hours of soaking and allowed to dry for 24 hours. The wetting and drying cycle was repeated 12 times; a new supply of water was used for each cycle. At the end of the twelfth cycle each bundle was twisted one turn per inch of S-twist, and then mounted on boards for tests of strength in the same manner as for dry strength. Two tests were made of each bundle. The average strength and standard error and average elongation and standard error were calculated from the 50 test results of each fiber lot.

The above procedure was repeated but water containing 3.7 percent of sea salt was used instead of tap water. The salt water was renewed for each wetting and drying cycle.

\section{MATERIALS TESTED}

The fibers tested included six lots of abaca (manila), nine of sisal, two of jute, two of henequen, one of pita floja, one of ixtle, four of sansevieria, one of palmetto, three of hemp, two of roselle, one of manzanita, one of malvita, and two of yucca. The number assigned to each fiber and information as to grade, source, housemark, and date of baling, which are considered important in the cordage industry, are given in table 1 . 
TABLE 1.-Description, fineness, and breaking strength of cordage fibers [The standard error a is given immediately after each value in the table]

\begin{tabular}{|c|c|c|c|c|c|c|c|c|c|c|c|}
\hline \multirow{3}{*}{ Number } & \multirow{3}{*}{ Fiber } & \multirow{3}{*}{ Description and grade } & \multirow{3}{*}{$\begin{array}{l}\text { Number of } \\
\text { fibers per } \\
\text { 15-in. bundle } \\
\text { weighing } 5 \\
\text { grains }\end{array}$} & \multirow{3}{*}{$\begin{array}{c}\text { Fineness of } \\
\text { flber }\end{array}$} & \multirow{3}{*}{$\begin{array}{c}\text { Breaking } \\
\text { length of } \\
\text { dry } \\
\text { bundle }\end{array}$} & \multirow{2}{*}{\multicolumn{2}{|c|}{$\begin{array}{l}\text { Breaking strength of } \\
\text { bundle }\end{array}$}} & \multicolumn{4}{|c|}{ Dry breaking strength after- } \\
\hline & & & & & & & & \multicolumn{2}{|c|}{$\begin{array}{l}\text { Soaking in fresh } \\
\text { water for- }\end{array}$} & \multicolumn{2}{|c|}{$\begin{array}{l}\text { Soaking in salt } \\
\text { water for- }\end{array}$} \\
\hline & & & & & & Dry & Wet & 12 days & 28 days & 12 days & 28 days \\
\hline 1 & Abaca & aark TO/KSO/E. & $30 \pm 0.9$ & $\begin{array}{r}1,000 \mathrm{ft} / \mathrm{llb} \\
53 \pm 1.6\end{array}$ & $\begin{array}{c}1,000 / t \\
158 \pm 4.2\end{array}$ & $\begin{array}{c}l b \\
90 \pm 2.4\end{array}$ & $\begin{array}{c}l b \\
74 \\
\pm 1.8\end{array}$ & $\begin{array}{c}l b \\
68 \pm 2.4\end{array}$ & $\begin{array}{c}l b \\
49 \pm 1.6\end{array}$ & $\begin{array}{c}l b \\
93 \pm 2.0\end{array}$ & $\begin{array}{c}l b \\
83 \stackrel{2.3}{ \pm}\end{array}$ \\
\hline 2. & do & $\begin{array}{l}\text { Baling date Dec. } 1939 . \\
\text { Grade J2, Davao, Housemark DA/KC/J2. }\end{array}$ & $30=$ & $53 \pm 1.2$ & $180 \pm 2$ & $103 \pm 1.3$ & $96 \pm 1.9$ & $73 \pm 2.7$ & $28 \pm 2.0$ & $51 \pm 1.4$ & $58 \pm 1.7$ \\
\hline & & P. I.Govt., Grade I & $28 \pm 0.5$ & $49 \pm$ & ${ }^{*} 166 \pm 5.4$ & ${ }^{*} 95 \pm 3.1$ & ${ }^{*} 62 \pm 4.3$ & $84 \pm 1.5$ & $88 \pm 1.9$ & $85 \pm 1.9$ & $72 \pm 1.7$ \\
\hline & & $\begin{array}{l}\text { P.I. Govt,, Grade E, S F Co. Inc. Sta. Ana, } \\
\text { Davao 55-19C Mindanao, Nov. 17, 1936, } \\
\text { Da/SFC/E. }\end{array}$ & $55 \pm 1.1$ & $96 \pm$ & $*^{*} 14$ & $* 81 \pm 2.3$ & $* 57 \pm 2.6$ & $68 \pm 2.1$ & $61 \pm 2.0$ & $67 \pm 1.6$ & $67 \pm 1.3$ \\
\hline 5... & ...... do & $\begin{array}{l}\text { P. I. Govt., Grade F, Saleeby Fiber Co., } \\
\text { Manila } 6-220 \text { S. Can, Jan. } 10,1936, \mathrm{M} / \mathrm{Sec} / \mathrm{F} \text {. }\end{array}$ & $52 \pm 2.5$ & $91 \pm 4.4$ & ${ }^{*} 138 \pm 4.2$ & ${ }^{*} 79 \pm 2.4$ & ${ }^{*} 66 \pm 2.9$ & $87 \pm 3.3$ & $83 \pm 3.0$ & $85 \pm 2.4$ & $78 \pm 1.7$ \\
\hline 6.. & $\ldots$ & $\begin{array}{l}\text { P. I. Govt., Grade J1, Fobuana Plant Co., } \\
\text { Inc., Daliaom Davao, 57-136 S Min. Feb. }\end{array}$ & $46 \pm 0.9$ & $81 \pm 1.6$ & $* 133 \pm 4.2$ & $* 76 \pm 2.4$ & ${ }^{*} 59 \pm 2.8$ & $82 \pm 1.5$ & $77 \pm 2.0$ & $83 \pm 1.8$ & $70 \pm 1.4$ \\
\hline & Sisal. & $\begin{array}{l}\text { Grade 1, Housemark HIMO. Baling date } \\
\text { Aug. 1942. }\end{array}$ & $21 \pm 0.2$ & $37 \pm 0.4$ & $119 \pm 2.6$ & $68 \pm 1.5$ & $62 \pm 1.8$ & $63 \pm 1.3$ & $68 \pm 1.3$ & $72 \pm 1.5$ & $75 \pm 1.3$ \\
\hline & & $\begin{array}{l}\text { Grade } 1 \\
\text { Grade } 3 \overline{\mathrm{L}, \mathrm{H}} \text { ousemark LUCY. Baling date } \\
\text { Aug. } 1942 \text {. }\end{array}$ & $\begin{array}{l}23 \pm 0.2 \\
19 \pm 0.2\end{array}$ & $\begin{array}{l}40 \pm 0.4 \\
33 \pm 0.4\end{array}$ & $\begin{array}{l}119 \pm 3.0 \\
126 \pm 2.5\end{array}$ & $\begin{array}{l}68 \pm 1.7 \\
72 \pm 1.4\end{array}$ & $\begin{array}{l}63 \pm 1.4 \\
56 \pm 1.2\end{array}$ & $\begin{array}{l}63 \pm 1.3 \\
56 \pm 1.1\end{array}$ & $\begin{array}{l}61 \pm 1.2 \\
58 \pm 1.1\end{array}$ & $\begin{array}{l}72 \pm 1.4 \\
75 \pm 1.6\end{array}$ & $\begin{array}{l}74 \pm 1.7 \\
79 \pm 2.3\end{array}$ \\
\hline 10 & -.-.do & Grade $3 L_{2}$ & $24 \pm 0.3$ & $=0.5$ & $=2.3$ & 1.3 & & 69 & 64 & 6 & 18 \\
\hline & $-\cdots 0$ & African, Grade 8 & & & & & & & & & \\
\hline & $-\ldots d$ & Afric & & & & & & 68 & & & \\
\hline & - . do & African, Grade SLT3 & $27 \pm 0.5$ & $47=$ & 116 & & & 62 & 62 & 61 & $=1.0$ \\
\hline 14 & ...... do & African, Grade LLT-A & $37=$ & $65=$ & $=2.5$ & & & 64 & & & $=1.1$ \\
\hline & $--\bar{d}$ & Blend of several grades & $21 \pm 0.2$ & $37 \pm 0.4$ & $100 \pm 2.8$ & 1.6 & & $=0.9$ & 56 & 1.0 & $56 \pm 0.9$ \\
\hline 16. & Hene & Grade C \& M & $20 \pm 0.1$ & $35 \pm 0.2$ & $86 \pm 1.4$ & & & 46 & 47 & 54 & 52 \\
\hline & Pita f & Mexican, Grade A.... & $\begin{aligned} 21 \pm 0.2 \\
142 \pm 4.2\end{aligned}$ & $\begin{array}{r}37 \pm 0.4 \\
249+7.4\end{array}$ & 86 & & & & & & \\
\hline & Jute & High grade & ${ }^{* *} 500 \pm 17$ & $* * 880 \pm 30$ & $\begin{array}{r}152 \pm 2.3 \\
93 \pm 2.3\end{array}$ & $\begin{array}{l}87 \pm 1.3 \\
53 \pm 1.3\end{array}$ & $\begin{array}{l}61 \pm 1.2 \\
44 \pm 1.2\end{array}$ & $\begin{array}{l}55 \pm 1.5 \\
45 \pm 1.3\end{array}$ & $\begin{array}{l}53 \pm 2.1 \\
40 \pm 1.0\end{array}$ & $\begin{array}{l}80 \pm 1.9 \\
54 \pm 1.5\end{array}$ & $\begin{array}{l}76 \pm 2.2 \\
53 \pm 1.5\end{array}$ \\
\hline & . do & Low grade & $* * 280 \pm 55$ & $* * 490 \pm 96$ & $75 \pm 2.3$ & $43 \pm 1.3$ & $36 \pm 1.1$ & $40 \pm 1.0$ & $37 \pm 1.5$ & $\begin{array}{l}54 \pm 1.0 \\
38 \pm 1.1\end{array}$ & $41 \pm 1.2$ \\
\hline & Hemp & Wis., Line No. 1 . & $* * 160 \pm 18$ & $* * 280 \pm 32$ & $130 \pm 3.0$ & $74 \pm 1.7$ & $42 \pm 1.3$ & $44 \pm 1.1$ & $31 \pm 1.1$ & $59 \pm 1.8$ & $45 \pm 1.3$ \\
\hline & -...do do & Wis., Line No. 3. & $* * 100 \pm 7$ & $* * 175 \pm 12$ & $70 \pm 1.9$ & & & $29 \pm 1.0$ & & $33 \pm 1.2$ & \\
\hline & ......do_ & Kentucky & $* * 94 \pm 3$ & $* * 165 \pm 5$ & $58 \pm 2.6$ & $33 \pm 1.5$ & $19 \pm 0.9$ & $22 \pm 0.8$ & $26 \pm 1.0$ & $27 \pm 1.3$ & $31 \pm 1.1$ \\
\hline
\end{tabular}




\begin{tabular}{|c|c|c|c|c|c|c|c|c|c|c|c|}
\hline 24 & Roselle... & Hebiscus cannabinus (Kenaf) ... & $* * 154 \pm 6$ & $* * 270 \pm 11$ & $77 \pm 2.5$ & $44 \pm 1.4$ & $40 \pm 1.4$ & $44 \pm 1.6$ & $34 \pm 1.3$ & $33 \pm 1.4$ & $32 \pm 1.6$ \\
\hline & Manzanita..- & Malvaviscus Arboreus... & $* * 195 \pm 12$ & $* * 340 \pm 21$ & $56 \pm 2.3$ & $32 \pm 1.3$ & $30 \pm 0.9$ & $28 \pm 0.9$ & $33 \pm 1.1$ & $28 \pm 1.3$ & $28 \pm 1$ \\
\hline 26 & Malvita & Urena Lobata L & $* * 310 \pm 30$ & $* * 540 \pm 53$ & $53 \pm 2.3$ & $30 \pm 1.3$ & $35 \pm 1.3$ & $34 \pm 1.1$ & $28 \pm 1.0$ & $32 \pm 1.3$ & $30 \pm$ \\
\hline & Roselle ... & Hebiscus sabdariffa.. & $* * 164 \pm 8$ & $* * 287 \pm 14$ & $81 \pm 2.1$ & $46 \pm 1.2$ & $47 \pm 1.6$ & $44 \pm 1.4$ & $44 \pm 1.6$ & $42 \pm 1.6$ & $45 \pm 1$ \\
\hline 28 & Sansevieria.... & Metallica, Floridan & $* 120 \pm 2.8$ & $* 210 \pm 4.9$ & $144 \pm 3.3$ & $82 \pm 1.9$ & & & & & \\
\hline 29 & -....do... & Metallica, Floridan & $* 107 \pm 3.0$ & $* 187 \pm 5.3$ & $130 \pm 3.0$ & $74 \pm 1.7$ & & & & & \\
\hline 30 & - ndo do & Guineensis, Floridan & **79 74.2 & $* * 138 \pm 7.4$ & $152 \pm 4.4$ & $87 \pm 2.5$ & & & & & \\
\hline 31 & Y ucca do elata & African_.....- & $\begin{array}{r}* 94 \pm 2.3 \\
* * 97 \pm 5.2\end{array}$ & $\begin{array}{r}* 165 \pm 4.0 \\
* * 170 \pm 9.1\end{array}$ & $\begin{array}{l}137 \pm 2.8 \\
{ }_{*}=21 \pm 2.8\end{array}$ & $\begin{array}{r}78 \pm 1.6 \\
* 35 \pm 1.6\end{array}$ & & & & & \\
\hline $\begin{array}{l}32 \\
33 .\end{array}$ & Yucca macro- & Spanish bayonet.... & $* * 30 \pm 1.3$ & $* * 53 \pm 2.3$ & $* * 128 \pm 4.0$ & $* * 73 \pm 2.3$ & & & & & \\
\hline 34 & $\begin{array}{l}\text { carpa. } \\
\text { Ixtle........ }\end{array}$ & Maguey, Mexican & $* * 21 \pm 0.7$ & $* * 37 \pm 1.2$ & ${ }^{*} 74 \pm 2.1$ & $* 42 \pm 1.2$ & & & & & \\
\hline & Palmetto... & & $* 16 \pm 1.0$ & $* 28 \pm 1.8$ & ${ }^{* *} 37 \pm 3.5$ & ${ }^{* *} 21 \pm 2.0$ & ${ }^{*} 24 \pm 2.2$ & & & & \\
\hline
\end{tabular}

- The standard error was computed by means of the expression $\sqrt{\frac{2 d^{2}}{n(n-1)}}$, where $d$ represents the deviations of the observed values from the average and $n$ represents the number of observed values. Two asterisks indicate that $n$ was 10 or more, one asterisk indicates that $n$ was 20 or more, and no asterisk indicates that $n$ was 50 or more. 
TABLE 1.-Description, fineness, and breaking strength of cordage fibers-Continued

\begin{tabular}{|c|c|c|}
\hline Number & Fiber & Description and grade \\
\hline 1. & Abaca_- & Grade E, Davao, Housemark TO/KS/O/E. \\
\hline 2. & $\ldots$ do & $\begin{array}{l}\text { Baling date Dec. } 1939 \text {. } \\
\text { Grade J2, Davao, Housemark DA/KC/J2. }\end{array}$ \\
\hline 3. & _...do. & $\begin{array}{l}\text { Baling date Sept. } 1941 . \\
\text { P. I. Govt., Grade } \mathrm{I}\end{array}$ \\
\hline & & $\begin{array}{l}\text { P. I. Govi., Grade E, S F Co. Inc., Sta. } \\
\text { Ana, Davao 55-19C Mindanao, Nov. 17, } \\
\text { 1936, Da/SF C/E. }\end{array}$ \\
\hline $5 \ldots$ & do & $\begin{array}{l}\text { P. I. Govt., Grade F, Saleeby Fiber Co., } \\
\text { Manila 6-220 S. Can. Jan. 10, 1936, M/ }\end{array}$ \\
\hline $6 \ldots$ & _....do_. & $\begin{array}{l}\text { P. I. Govt., Grade J1, Fobuana Plant Co., } \\
\text { Inc. Daliaom Davao, 57-136 S Min. Feb. } \\
\text { 7, 1936, DL/F PC/J1, Sup. Seconds. }\end{array}$ \\
\hline & Sisal_. & $\begin{array}{l}\text { Grade 1, Housemark HIMO. Baling date } \\
\text { Aug. 1942. }\end{array}$ \\
\hline & -.do do & Grade 1 \\
\hline & do & $\begin{array}{l}\text { Grade 3L, Housemark LUCY. Baling date } \\
\text { Aug. } 1942 \text {. }\end{array}$ \\
\hline & -..-do.. & Grade $3 \mathrm{~L}$ \\
\hline 12 & do & $\begin{array}{l}\text { African, Grade } 8 \\
\text { African, Grade } 3 \mathrm{~L}^{2}\end{array}$ \\
\hline 13. & _...do & African, Grade SLT3 \\
\hline & ---do do & African, Grade LLT-A \\
\hline $\begin{array}{ll}15- \\
16\end{array}$ & Henequen & $\begin{array}{l}\text { Blend of several grades } \\
\text { Grade C \& M }\end{array}$ \\
\hline & Pita do & Mexican, Grade A... \\
\hline & $\begin{array}{l}\text { Pita floja } \\
\text { Jute.......... }\end{array}$ & High grade.. \\
\hline & Hemp & Low grade \\
\hline 21. & Hemp.... & Wis., Line No. 1 \\
\hline & do & Kentucky \\
\hline
\end{tabular}

\begin{tabular}{|c|c|c|c|c|c|c|c|}
\hline \multicolumn{8}{|c|}{ Dry breaking strength after- } \\
\hline \multicolumn{2}{|c|}{$\begin{array}{l}12 \text { cycles of soaking and } \\
\text { drying in- }\end{array}$} & \multicolumn{3}{|c|}{ Heating to $105^{\circ} \mathrm{C}$ for- } & \multicolumn{3}{|c|}{$\begin{array}{l}\text { Exposure in twin arc Weather- } \\
\text { ometer for- }\end{array}$} \\
\hline $\begin{array}{l}\text { fresh } \\
\text { water }\end{array}$ & $\begin{array}{l}\text { salt } \\
\text { water }\end{array}$ & 10 days & 20 days & 30 days & 100 hours & 150 hours & 200 hours \\
\hline $81 \pm 1.5$ & $\begin{array}{l}l b \\
88 \pm 1.8\end{array}$ & $*_{85}^{l b} \pm 1.8$ & $\stackrel{l b}{l b} \pm 2.6$ & ${ }^{l b}{ }_{52 \pm 2.6}$ & ${ }^{2} 60 \pm 1.3$ & $l b$ & 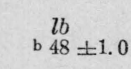 \\
\hline $74 \pm 2.5$ & $54 \pm 1.8$ & $* 75 \pm 1.6$ & $* 54 \pm 1.5$ & ${ }^{*} 48 \pm 1.5$ & $* 59 \pm 2.0$ & $*_{51} \pm 1.2$ & $* 44 \pm 1.9$ \\
\hline $\begin{array}{l}76 \pm 2.2 \\
62 \pm 2.7\end{array}$ & $\begin{array}{l}76 \pm 2.4 \\
64 \pm 1.4\end{array}$ & $\begin{array}{l}* 74 \pm 2.0 \\
* 70 \pm 2.9\end{array}$ & $\begin{array}{l}* 67 \pm 1.8 \\
* 58 \pm 3.1\end{array}$ & $\begin{array}{l}* 60 \pm 2.0 \\
*_{47} \pm 2.2\end{array}$ & $\begin{array}{l}{ }^{*} 52 \pm 3.7 \\
* 33 \pm 2.5\end{array}$ & $\begin{array}{l}{ }^{*} 49 \pm 3.7 \\
* 31 \pm 2.6\end{array}$ & $\begin{array}{l}* 18 \pm 2.4 \\
* 37 \pm 3.3\end{array}$ \\
\hline $82 \pm 3.8$ & $85 \pm 2.5$ & $* 68 . \pm 2.1$ & ${ }^{*} 56 \pm 2.0$ & $45 \pm 2.8$ & $* 40 \pm 2.9$ & $* 42 \pm 3.0$ & $* 31 \pm 2.5$ \\
\hline $80 \pm 1.7$ & $72 \pm 2.1$ & $* 74 \pm 1.6$ & $* 72 \pm 1.4$ & $* 69 \pm 2.0$ & ${ }^{*} 48 \pm 3.2$ & $*_{49} \pm 4.2$ & $* 45 \pm 2.0$ \\
\hline $63 \pm 1.4$ & $72 \pm 1.3$ & ${ }^{*} 62 \pm 1.4$ & $*_{56} \pm 1.3$ & $*_{51} \pm 1.3$ & $*_{51} \pm 2.2$ & & b 0 \\
\hline $\begin{array}{l}70 \pm 1.3 \\
58 \pm 1.3\end{array}$ & $\begin{array}{l}60 \pm 1.3 \\
68 \pm 1.2\end{array}$ & $\begin{array}{l}* 59 \pm 1.1 \\
{ }^{*} 67 \pm 1.4\end{array}$ & $\begin{array}{l}*_{51} \pm 1.5 \\
{ }_{6} 62 \pm 1.5\end{array}$ & $\begin{array}{l}*_{44} \pm 1.2 \\
*_{57} \pm 1.4\end{array}$ & $\begin{array}{l}{ }^{*} 39 \pm 2.6 \\
{ }^{5} 57 \pm 1.6\end{array}$ & ${ }^{4} 48 \pm 2.8$ & $\begin{array}{r}\mathrm{b} 0 \\
0\end{array}$ \\
\hline $\begin{array}{l}73 \pm 1.2 \\
63 \pm 1.5 \\
60 \pm 1.1 \\
68 \pm 0.9 \\
66 \pm 1.1 \\
55 \pm 0.9 \\
53 \pm 1.0 \\
53 \pm 0.7 \\
81 \pm 1.4 \\
47 \pm 1.4 \\
41 \pm 1.2 \\
45 \pm 1.6 \\
28 \pm 1.1 \\
27 \pm 1.0\end{array}$ & $\begin{array}{l}73 \pm 1.2 \\
55 \pm 1.1 \\
58 \pm 1.0 \\
57 \pm 1.4 \\
65 \pm 1.2 \\
54 \pm 0.9 \\
53 \pm 0.8 \\
49 \pm 0.7 \\
87 \pm 2.0 \\
51 \pm 1.4 \\
39 \pm 1.7 \\
49 \pm 1.4 \\
33 \pm 1.0 \\
31 \pm 1.1\end{array}$ & 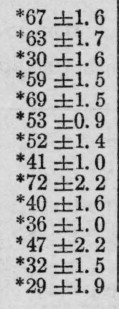 & 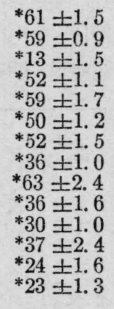 & 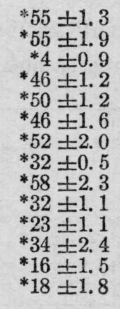 & 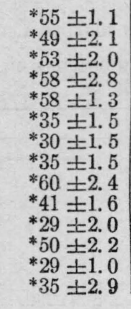 & $\begin{array}{l}* 34 \pm 3.4 \\
*_{39} \pm \pm 2.8 \\
*_{46} \pm 2.5 \\
*_{50} \pm 1.9 \\
* 22 \pm 1.7\end{array}$ & $\begin{array}{c}\text { b } 0 \\
* 19 \pm 3.9 \\
*_{4} \pm 2.2 \\
* 6 \pm 3.2 \\
* 16 \pm 3.3 \\
0 \\
0 \\
\text { b } 1 \pm 0.5 \\
\text { b } 0 \\
\text { b } 49 \pm 1.5 \\
\text { b } 15 \pm 2.6 \\
\text { b } 0.6 \\
* 35 \pm 1.1 \\
* 24 \pm 1.2 \\
* 27 \pm 1.4\end{array}$ \\
\hline
\end{tabular}




\begin{tabular}{|c|c|c|c|c|c|c|c|c|c|c|}
\hline 24 & $\begin{array}{l}\text { Roselle } \\
\text { Manzanita.... } \\
\text { Malvita } \\
\text { Roselle }\end{array}$ & $\begin{array}{l}\text { Hebiscus cannabinus (Kenaf) } \\
\text { Malvaviscus Arboreus..... } \\
\text { Urena Lobata L } \\
\text { Hebiscus sabdariffa }\end{array}$ & $\begin{array}{l}35 \pm 1.1 \\
31 \pm 1.3 \\
30 \pm 1.0 \\
40 \pm 1.6\end{array}$ & $\begin{array}{l}39 \pm 1.1 \\
29 \pm 1.3 \\
32 \pm 1.3 \\
38 \pm 1.8\end{array}$ & $\begin{array}{l}* 40 \pm 1.7 \\
* 31 \pm 1.9 \\
* 37 \pm 2.1 \\
* 47 \pm 2.2\end{array}$ & $\begin{array}{l}* 35 \pm 2.0 \\
* 27 \pm 1.6 \\
* 39 \pm 1.7 \\
* 50 \pm 1.5\end{array}$ & $\begin{array}{l}* 30 \pm 1.8 \\
* 28 \pm 1.4 \\
* 32 \pm 2.0 \\
* 35 \pm 2.0\end{array}$ & $\begin{array}{l}* 42 \pm 2.4 \\
* 26 \pm 2.6 \\
* 23 \pm 2.5 \\
* 33 \pm 2.3\end{array}$ & $\begin{aligned} * 27 \pm 2.1 \\
{ }^{*} 13 \pm 2.1 \\
{ }^{*} 7 \pm 1.8 \\
*_{21} \pm 2.1\end{aligned}$ & $\begin{aligned} * 18 & \pm 2.0 \\
* 8 & \pm 2.3 \\
{ }^{*} 5 \pm 1.6 & \pm\end{aligned}$ \\
\hline & Sansevieria.... & $\begin{array}{l}\text { Metallica, Floridan } \\
\text { Metallica, Floridan }\end{array}$ & & - & & & & & & \\
\hline & do & Guineensis, Floridan & & & & & & & & \\
\hline 31. & Y... do & African & & & & & & & & \\
\hline & Yucca macro- & Spanish bayonet.- & & & & & & & & \\
\hline & $\begin{array}{l}\text { carpa. } \\
\text { Ixtle...... }\end{array}$ & Maguey, Mexican & & & & & & & & \\
\hline & & & & & & & & & & \\
\hline
\end{tabular}

b The value is for an exposure of 183 hours in Weather-ometer. 


\section{RESULTS}

In table 1 are also given the following data: Number of fibers per bundle; fineness of fiber; breaking length; dry and wet breaking strength; and dry breaking strengths after (a) soaking in fresh and in salt water, (b) alternate wetting and drying with fresh and with salt water, (c) exposure to a temperature of $105^{\circ} \mathrm{C}$, and (d) exposure to light and intermittent spraying with water in a Weather-ometer. The standard error is also given for each value reported in the table. All the values are based on bundles of fibers weighing 5 grains and 15 in. long.

In table 2 are given the following data: Dry and wet elongation at rupture; dry elongation at rupture after soaking in fresh and in salt water; and dry elongation after alternate wetting and drying by the use of fresh or salt water. The flexural endurance, the resistance to abrasion for S-twist in the bundles of fibers and S-twist in the ply of two bundles, and the resistance to abrasion for S-twist in the bundles of fibers, and Z-twist in the ply of two bundles are also given in table 2 . The standard error is given for the dry and wet elongation values. 
TABLE 2.-Elongation, flexural endurance, and resistance to abrasion of cordage fibers

\begin{tabular}{|c|c|c|c|c|c|c|c|c|c|c|c|c|c|c|c|}
\hline \multirow{3}{*}{ Number } & \multirow{3}{*}{ Fiber } & \multicolumn{2}{|c|}{ Elongation at rupture } & \multicolumn{6}{|c|}{ Dry elongation at rupture after- } & \multicolumn{2}{|c|}{$\begin{array}{c}\text { Flexural endurance } \\
\text { at- }\end{array}$} & \multicolumn{4}{|c|}{ Resistance to abrasion for- } \\
\hline & & \multirow{2}{*}{ Dry } & \multirow{2}{*}{ Wet } & \multicolumn{2}{|c|}{$\begin{array}{l}\text { Soaking in fresh } \\
\text { water for- }\end{array}$} & \multicolumn{2}{|c|}{$\begin{array}{l}\text { Soaking in salt } \\
\text { water for- }\end{array}$} & \multicolumn{2}{|c|}{$\begin{array}{l}12 \text { eycles of soaking } \\
\text { and drying in - }\end{array}$} & \multirow{2}{*}{$\begin{array}{c}50 \% \text { of } \\
\text { original } \\
\text { strength }\end{array}$} & \multirow{2}{*}{$\begin{array}{l}\text { Strength } \\
\text { of } 20 \mathrm{lb}\end{array}$} & \multicolumn{2}{|c|}{ SS a twist at- } & \multicolumn{2}{|c|}{ SZ b twist at- } \\
\hline & & & & 12 days & 28 days & 12 days & 28 days & $\begin{array}{l}\text { Fresh } \\
\text { water }\end{array}$ & $\begin{array}{l}\text { Salt } \\
\text { water }\end{array}$ & & & $\begin{array}{l}50 \% \text { of } \\
\text { original } \\
\text { strength }\end{array}$ & $\begin{array}{l}\text { Strength } \\
\text { of } 20 \mathrm{lb}\end{array}$ & $\begin{array}{l}50 \% \text { of } \\
\text { original } \\
\text { strength }\end{array}$ & $\begin{array}{l}\text { Strength } \\
\text { of } 20 \mathrm{lb}\end{array}$ \\
\hline & & $\%$ & $\%$ & & & & & & & Cycles & Cycles & Cycles & Cycles & Cycles & Cycles \\
\hline & Abaca & - $2.1 \pm 0.06$ & $02.4 \pm 0.17$ & 2.8 & 2.1 & 2.3 & 2.8 & 2.5 & 3.2 & 475 & 950 & 900 & 1,400 & 1,400 & 2,200 \\
\hline & - & $2.8 \pm 0.11$ & $4.0 \pm 0.12$ & 3.4 & 2.1 & 2.6 & 3.1 & 3.5 & 2.2 & 215 & $\begin{array}{r}550 \\
750\end{array}$ & 800 & 1, & 1,800 & 2,900 \\
\hline & - do & $* 1.9 \pm 0.15$ & $-2-2-2-1$ & 2.7 & $\begin{array}{l}3.1 \\
2.0\end{array}$ & $\begin{array}{l}3.0 \\
2.4\end{array}$ & 2.9 & $\begin{array}{l}3.0 \\
2.6\end{array}$ & 2.8 & 300 & $\begin{array}{l}750 \\
525\end{array}$ & $\begin{array}{l}770 \\
750\end{array}$ & $\begin{array}{l}1,220 \\
1,120\end{array}$ & $\begin{array}{l}1,350 \\
3,400\end{array}$ & $\begin{array}{l}2,100 \\
5,000\end{array}$ \\
\hline & do & $* 2.8 \pm 0.19$ & & 2.7 & 2.9 & 3. 2 & 3.0 & 3. 3 & 3. 0 & 900 & 1,350 & 1,280 & 1,900 & 4,900 & 7,500 \\
\hline & - do & $* 3.3 \pm 0.19$ & & 3.1 & 3.1 & 3. 4 & 2. & 3.4 & 3.3 & 750 & 1,150 & 2,930 & 4, & 6,400 & 12,000 \\
\hline & Sisal .... & $2.6 \pm 0.08$ & $2.9 \pm 0.11$ & 2.3 & 2.7 & 2.8 & 3.4 & 2.5 & 2.7 & 550 & 1,100 & 1,050 & 1,500 & 4. 500 & 6,200 \\
\hline & ..... do & $2.7 \pm 0.07$ & 4. 0 & 3.1 & 3.1 & 4.3 3 & 3.8 & 2.5 & 3.6 & 500 & 950 & 2,300 & 3,300 & 11,000 & 16,000 \\
\hline $9 \ldots \ldots$ & ..... do & $2.5 \pm 0.04$ & 3. $0=$ & 2.8 & 2.4 & 2.6 & 2.6 & 2.5 & 2.8 & 425 & 900 & 600 & & 6 , & 8,500 \\
\hline $10 \ldots \ldots$ & ..... do & $3.0 \pm 0.06$ & $2.7 \pm 0.07$ & 2.8 & 2.3 & 3. & 3. & 3. & 3. 0 & 550 & 1,600 & 750 & 1, & 5,0 & 7,800 \\
\hline & ..... do & $3.3 \pm 0.08$ & $3.8=$ & 3. & 3. & 4. & 2. & 3. & 3. & 875 & 1,550 & 1,4 & 2,1 & 20,000 & 29,000 \\
\hline & -.... do & $2.6 \pm 0.07$ & $2.6=$ & & 3. & 3. & 3. & 3. & 2. & & 1,1 & 1,3 & & & 3,800 \\
\hline & -.... do & $3.3 \pm 0.10$ & $4.4 \pm 0.11$ & 3.2 & 3.5 & 3. & 3. & 3.5 & 2.8 & 425 & 1,200 & 1,250 & 1, & 22,000 & 30.500 \\
\hline 14 & -...-do. & $3.4 \pm 0.10$ & $3.6 \pm 0$. & 3. 5 & 3. 1 & 3.2 & 3. & 3.5 & 3. 6 & 600 & 1,200 & 1,350 & & 5 & 8,200 \\
\hline & Hedo & $2.9 \pm 0.10$ & & 3.2 & 3. 0 & 3.6 & 2. & 3.2 & 2.6 & 550 & 950 & 4,500 & 6, & 30, & 38,000 \\
\hline $\begin{array}{l}16 \\
17\end{array}$ & Henequen..... & $4.9 \pm 0.07$ & $6.0 \pm 0$ & 4.6 & 4. 3 & 5.1 & 6. & 5.5 & 5.2 & 1,350 & 1,900 & 1,900 & 2,200 & 16,000 & 19,000 \\
\hline & - Pita do & $4.4 \pm 0.08$ & 5. 4 & 4. & 4. & 5.9 & 5. & 5. 0 & 5. & 1,750 & 2, & 2,500 & 2,900 & 44,000 & 54,000 \\
\hline & Pita floja & $3.4 \pm 0.09$ & $3.6=$ & 2. & 2. & 3. & 4. & 3. & 3. & 275 & 1,2 & 150 & 250 & 220 & 370 \\
\hline & Jute & $1.7 \pm 0.07$ & $1.5 \pm 0$. & 1.3 & 1.3 & 1.4 & 1. & 1.2 & 1. & 420 & 71 & & 250 & 2,500 & 3,200 \\
\hline & do do & $1.3 \pm 0.04$ & $1.3 \pm 0.06$ & 1.3 & 1.1 & 1.0 & 1.8 & 1.2 & 1.7 & 560 & 620 & 170 & 190 & 1,000 & 1,050 \\
\hline & Hemp & $1.5 \pm 0.10$ & & 2. 2 & 1.6 & 1.8 & 2. 0 & 1.8 & 2.3 & 320 & 1,250 & 25 & 350 & 650 & 950 \\
\hline & $\ldots$ & $2.4 \pm 0.12$ & $2.3 \pm 0.12$ & 2.6 & 1.3 & 2.3 & 1. & 2. 2 & 2. & 200 & 200 & 22 & 225 & 5 & 775 \\
\hline & - & $1.5 \pm 0.06$ & $1.4=$ & 1.0 & 1.0 & 1.3 & 1. & 1. & 1. & 20 & 15 & 12 & 100 & 425 & 350 \\
\hline & selle. & $1.7 \pm 0.07$ & $2.1 \pm 0$. & 1.8 & 1.7 & 1.4 & 1. & 1. & 1. & 19 & 22 & 2 & 300 & 4,250 & 4,600 \\
\hline & Manzanita. & $1.6 \pm 0.05$ & $1.6 \pm 0.06$ & 1.2 & 1.2 & 1.2 & 1. & 1.2 & 1. & 45 & 33 & 1. & 85 & 1,850 & 1,450 \\
\hline & Malvita & $0.9 \pm 0.04$ & $1.3 \pm 0.05$ & 1.0 & 1.0 & 1.1 & 0. & 1.1 & 1. & 43 & 30 & 2 & 150 & & 6,500 \\
\hline 27 & Roselle & $1.7 \pm 0.06$ & $1.8 \pm 0.06$ & 1.4 & 1.4 & 1.5 & 1.3 & 1.4 & 1.5 & 400 & 450 & 255 & 285 & 3,600 & 4,100 \\
\hline $\begin{array}{l}28 \\
29\end{array}$ & Sansevieria. & $\begin{array}{l}4.7 \pm 0.25 \\
3.5 \pm 0.14\end{array}$ & -1 & $\ldots$ & we & & & & & & & & & & \\
\hline & do & $\begin{array}{r}3.5 \pm 0.14 \\
* 4.1 \pm 0.13\end{array}$ & & & & & & & & & - & & -.. & -1 & $\cdots$ \\
\hline & $-\mathrm{do}_{-}$ & $3.7 \pm 0.15$ & & & & & & & & & & & & & $\ldots$ \\
\hline $\begin{array}{l}32 \\
33\end{array}$ & Yucca & $\begin{array}{l}* 4.3 \pm 0.14 \\
* * 4.6 \pm 0.21\end{array}$ & 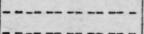 & $\cdots$ & & & & & & 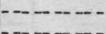 & $\ldots$ & - & & $\ldots$ & - \\
\hline & Ixtle........... & $\begin{array}{l}4.0 \pm 0.21 \\
4.5 \pm 0.15\end{array}$ & $-8-1-10-1$ & & & & & & & & & & & & 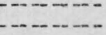 \\
\hline & Palmetto.... & $* * 1.7 \pm 0.09$ & ${ }^{* *} 1.0 \pm 0.10$ & & & & & & & 100 & & & & & \\
\hline
\end{tabular}

a SS indicates an S-twist in the bundle of fibers and an S-twist in the ply of two bundles.

b SZ indicates an S-twist in the bundle of fibers and a Z-twist in the ply of two bundles.

- Standard error, see footnote a of table 1. 


\section{DISCUSSION OF RESULTS}

\section{FINENESS OF FIBER}

The average number of fibers per bundle varied from about 20 for sisal, henequen and palmetto, to 500 for jute. The fineness of fiber varied from about $30,000 \mathrm{ft} / \mathrm{lb}$ for the coarser fibers to over $800,000 \mathrm{ft} / \mathrm{lb}$ for the fine jute fiber. The variation in fineness of fiber was great for a given kind of fiber. It ranged, for example, from 49,000 to $96,000 \mathrm{ft} / \mathrm{lb}$ for abaca, 33,000 to $65,000 \mathrm{ft} / \mathrm{lb}$ for sisal, and 165,000 to $280,000 \mathrm{ft} / \mathrm{lb}$ for hemp.

\section{BREAKING STRENGTH AND ELONGATION, DRY AND WET}

The breaking length expresses the breaking strength per unit weight of unit length of the bundle of fibers. The values given in table 1 for the bundle are lower than the values which would be obtained for the single fiber, because the strength of the fiber is

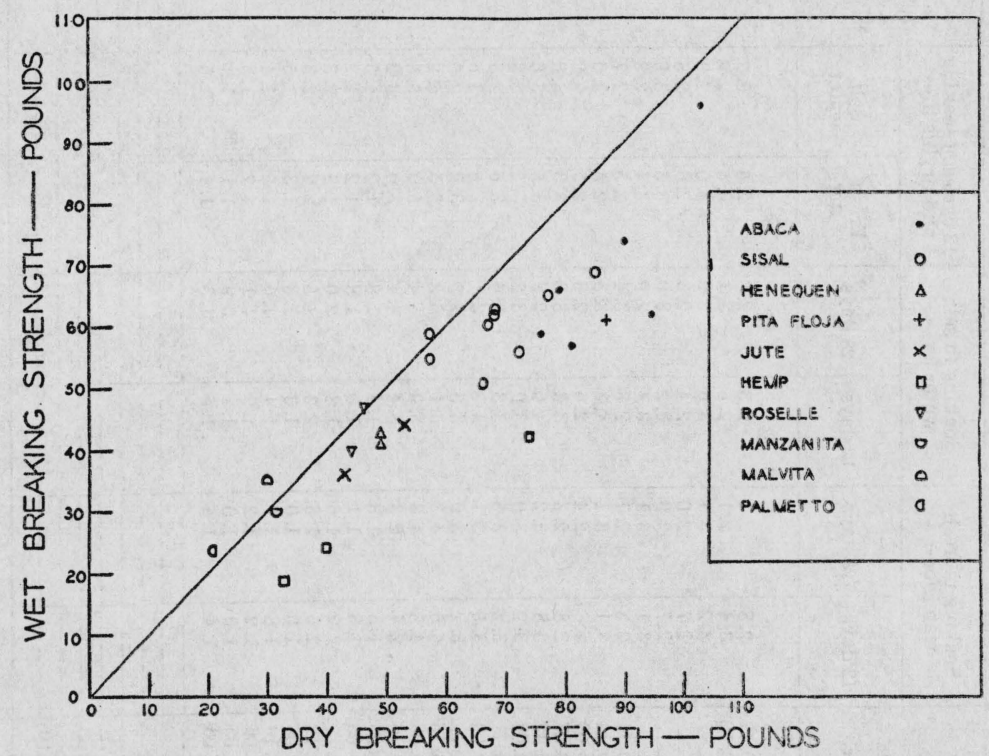

FIGURE 8.-Relation between dry and wet breaking strength of cordage fibers.

not fully realized when a group of fibers are tested simultaneously as in a bundle of fibers. The breaking lengths of the abaca fibers for the bundle, table 1, range from 138,000 to $180,000 \mathrm{ft}$. The average breaking length of different grades of abaca determined from tests of individual fibers ranged from about 175,000 to 250,000 ft, according to Becker. ${ }^{1}$ On the other hand, and for the same

1 Genevieve Becker, Color of abaca fiber in relation to deterioration by weathering, Cord Age 28, 24, 26, 28, and 30 (Dec. 1938). 
reason, the breaking lengths for the bundle of fibers are higher than those which would be obtained for ropes made from these fibers. The values obtained in this laboratory by Mease $^{2}$ for a variety of sizes of rope made from different grades of abaca ranged from 32,000 to $56,000 \mathrm{ft}$. The breaking lengths for the bundle, however, give a good indication of the relative intrinsic strength of the various fibers. The strength of ropes made from these fibers would be expected to be in the same relative order. A variation in the relative order would indicate either a more or a less efficient realization of the strength of the bundle of fibers when made into rope. Whether or not the strength of the bundle of different kinds of fibers is realized to varying degrees in ropes can only be determined by tests of bundles of fibers and ropes made from them.

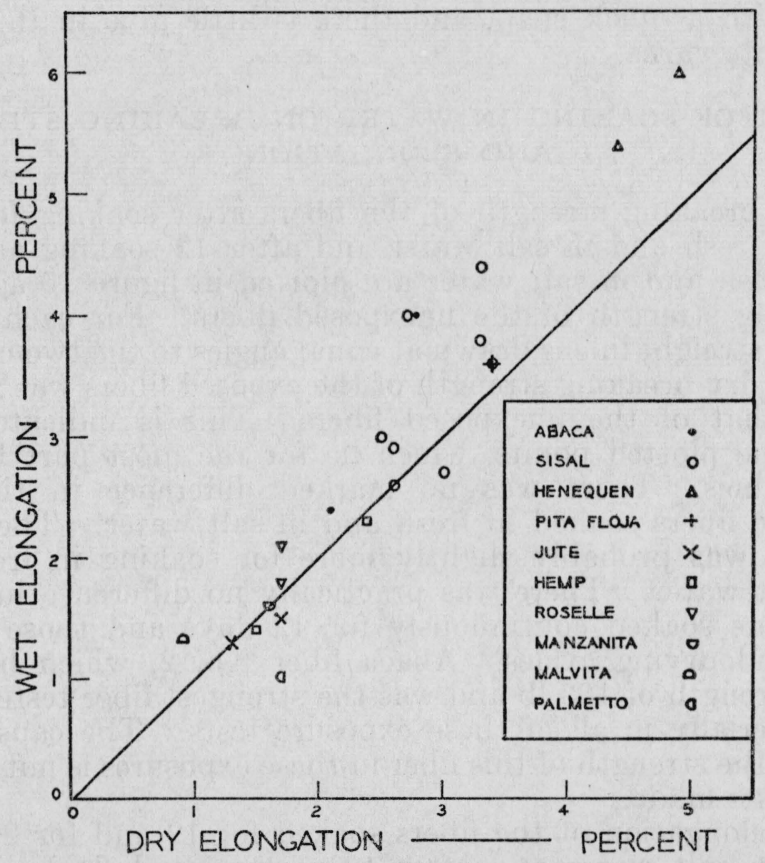

Figure 9.-Relation between dry and wet elongation of cordage fibers.

The wet strength of the bundles of fibers was in general lower than the dry strength. This is clearly shown in figure 8 where the wet strength is plotted against the dry strength. The plotted points lie for the most part below the straight line drawn at equal angles to the two coordinate axes. Since the points for a given kind of fiber are considerably scattered, no definite advantage of one kind of fiber over the other is indicated with respect to dry versus wet strength. .

\footnotetext{
2 Unpublished data.
} 
The wet elongation of the bundles of fibers was in general greater than the dry elongation. This is indicated in figure 9 where the wet elongation is plotted against the dry elongation. The plotted points lie for the most part above the straight line drawn at equal angles to the two coordinate axes. The henequen fibers had the highest elongation of the fibers tested, although their strength was less than for many of the other fibers. The jute fibers, which had approximately the same strength as the henequen fibers, were among those fibers having the lowest elongation. On the basis of these results, henequen would be superior to jute in its ability to withstand impact loads. The low stretch, and therefore low impact strength, of jute yarns has long been recognized. The extensive use of jute for wrapping twine by the United States Post Office Department is attributed to these characteristics. The jute yarn is readily broken by hand with a quick snap, and there is little give in the package tied with jute yarns.

\section{EFFECT OF SOAKING IN WATER ON BREAKING STRENGTH AND ELONGATION}

The dry breaking strength of the fibers after soaking for 12 and 28 days in fresh and in salt water and after 12 soaking and drying cycles in fresh and in salt water are plotted in figure 10 against the dry breaking strength of the unexposed fibers. For each exposure condition a straight line is drawn at equal angles to the two coordinate axes. The dry breaking strength of the exposed fibers was in general less than that of the unexposed fibers. This is indicated in the figure by the plotted points, which lie for the most part below the 45-degree lines. There was no marked difference in the results between the fibers soaked in fresh and in salt water. The decrease in strength was probably slightly more for soaking in fresh water than in salt water. There was practically no difference in strength for the fibers soaked continuously for 12 days and those given 12 soakings and drying cycles. Abaca fiber No. 2, which had a dry breaking strength of $103 \mathrm{lb}$ and was the strongest fiber tested, deteriorated materially in all of these exposure tests. The cause for the decrease of the strength of this fiber in these exposures is not apparent from the tests made.

The dry elongation of the fibers soaked for 12 and for 28 days in fresh and in salt water and after 12 soaking and drying cycles in fresh and in salt water is plotted in figure 11 against the dry elongation of the unexposed fibers. For each exposure condition a straight line is drawn at equal angles to the two coordinate axes. The dry elongation of the exposed fibers was in general slightly greater than that of the unexposed fibers. This is indicated in the figure by the plotted points, which lie for the most part above the 45-degree lines. There was no marked difference in the results between the fibers soaked in fresh and in salt water. The increase in elongation is probably slightly less for fibers soaked in fresh water than in salt water. There was practically no difference in elongation for the fibers soaked continuously for 12 days and those given 12 soaking and drying cycles. 


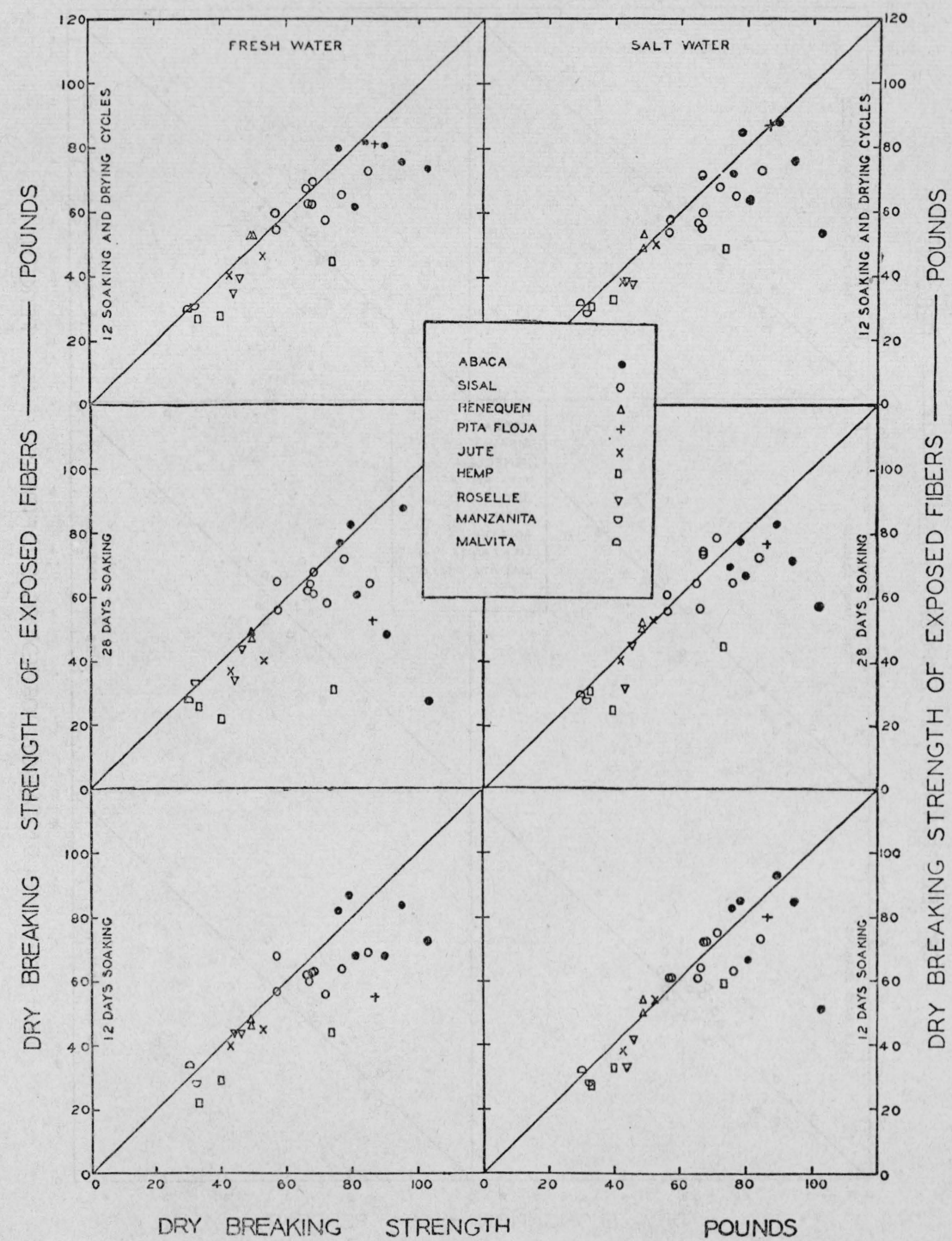

Figure 10.-Relation between dry breaking strength of cordage fibers and their dry breaking strength after soaking in fresh and in salt water. 
334 Journal of Research of the National Bureau of Standards

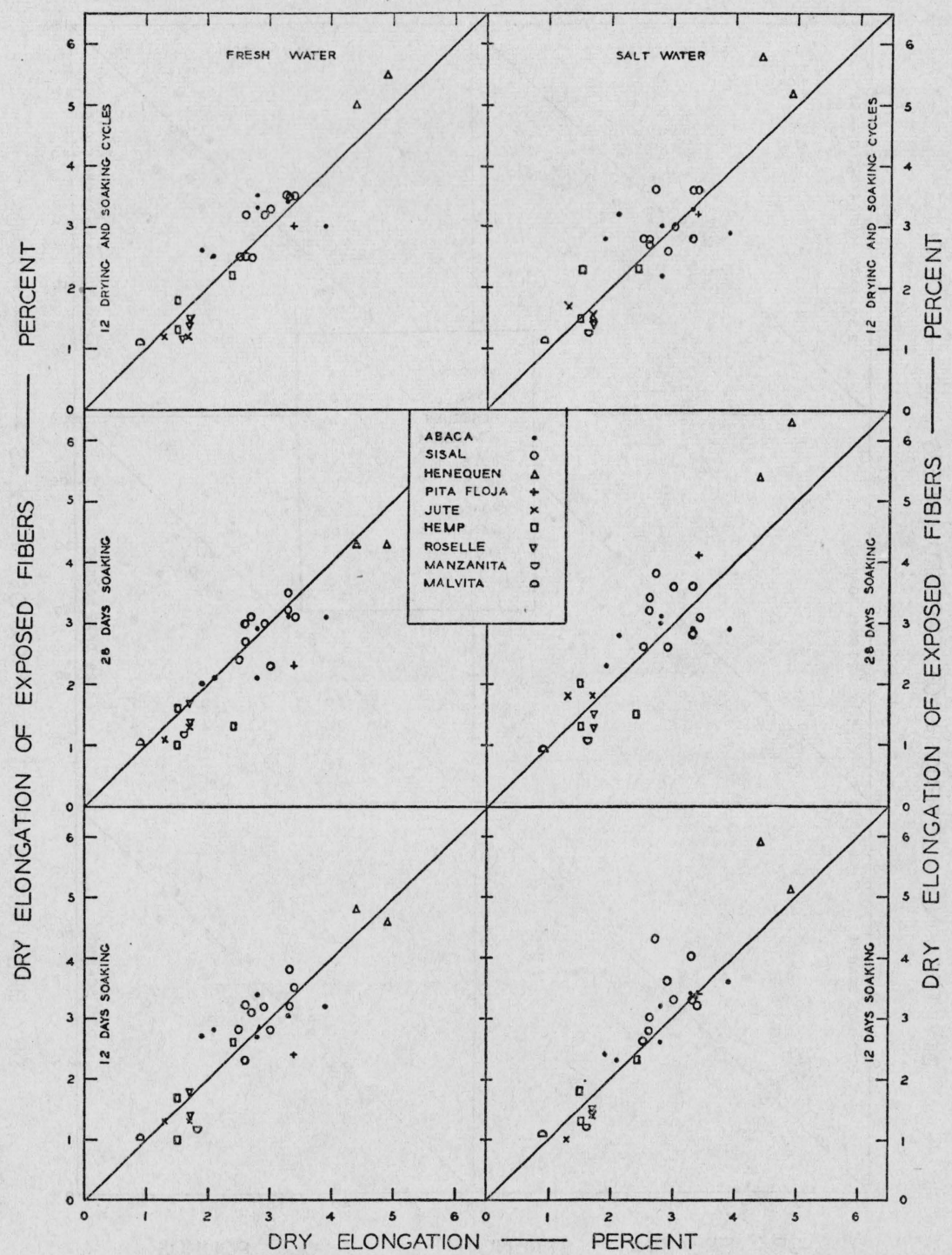

Figure 11.-Relation between dry elongation of cordage fibers and their dry elongation after soaking in fresh and in salt water. 


\section{EFFECT OF TEMPERATURE ON BREAKING STRENGTH}

The dry breaking strength of the fibers decreased materially with the number of days they were exposed to a temperature of $105^{\circ} \mathrm{C}$. This is clearly shown in the left portion of figure 12, where the dry breaking strength of the exposed fibers is plotted against the dry strength of the unexposed fibers. The plotted points in general fall considerably below the straight line drawn at equal angles to the two

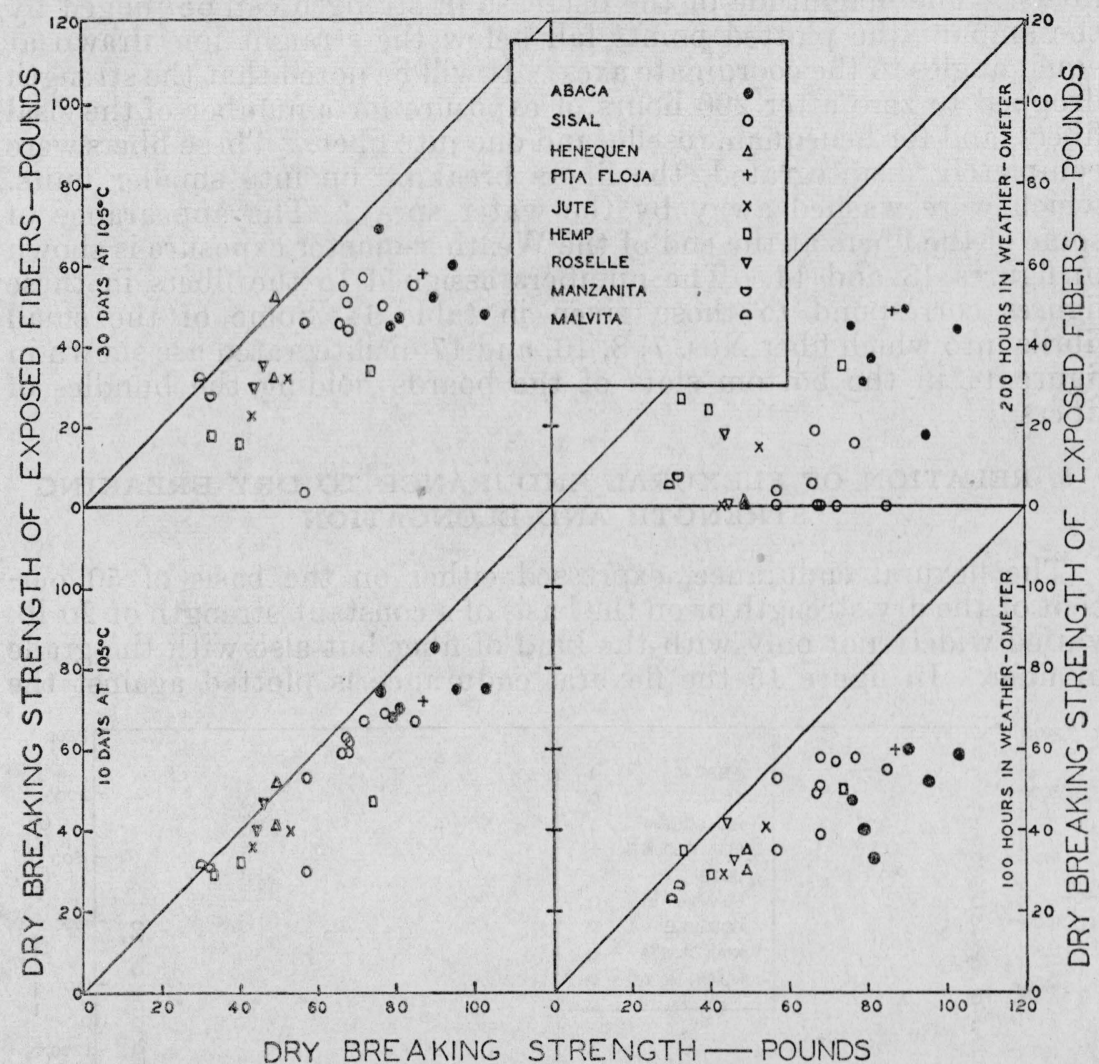

FIGURE 12.-Relation between dry breaking strength of cordage fibers and their dry breaking strength after exposure to elevated temperature and to accelerated weathering in a Weather-ometer.

coordinate axes. This was especially true after 30 days of exposure. Abaca fiber No. 2, in particular, dropped to less than 50 percent of its unexposed dry strength. This decrease in strength is comparable to that noted in the previous section for this fiber. The decrease in strength of sisal No. 12 was exceptionally large, amounting to 47 percent and 93 percent after 10 days and 30 days of exposure, respectively. 


\section{EFFECT OF ACCELERATED WEATHERING ON BREAKING STRENGTH}

The dry breaking strength of the fibers decreased markedly with the number of hours of exposure to light and intermittent spraying with fresh water in the Weather-ometer. This decrease is shown in the right portion of figure 12 , where the dry breaking strength of the exposed fibers is plotted against the dry strength of the unexposed fibers. The magnitude of the decrease in strength can be judged by the amount the plotted points fall below the straight line drawn at equal angles to the coordinate axes. It will be noted that the strength dropped to zero after 200 hours of exposure for a number of the sisal fibers, and for henequan, roselle, and one jute fiber. These fibers were completely disintegrated, the fibers breaking up into smaller units, which were washed away by the water spray. The appearance of some of the fibers at the end of the Weather-ometer exposure is shown in figures 13 and 14. The numbers assigned to the fibers in these figures correspond to those given in table 1. Some of the small fibrils into which fiber Nos. 7, 8, 10, and 17 disintegrated are shown in figure 14 in the bottom slots of the boards holding the bundles of fibers.

\section{RELATION OF FLEXURAL ENDURANCE TO DRY BREAKING STRENGTH AND ELONGATION}

The flexural endurance, expressed either on the basis of 50 percent of the dry strength or on the basis of a constant strength of $20 \mathrm{lb}$, varied widely not only with the kind of fiber but also with the grade of fiber. In figure 15 the flexural endurance is plotted against the

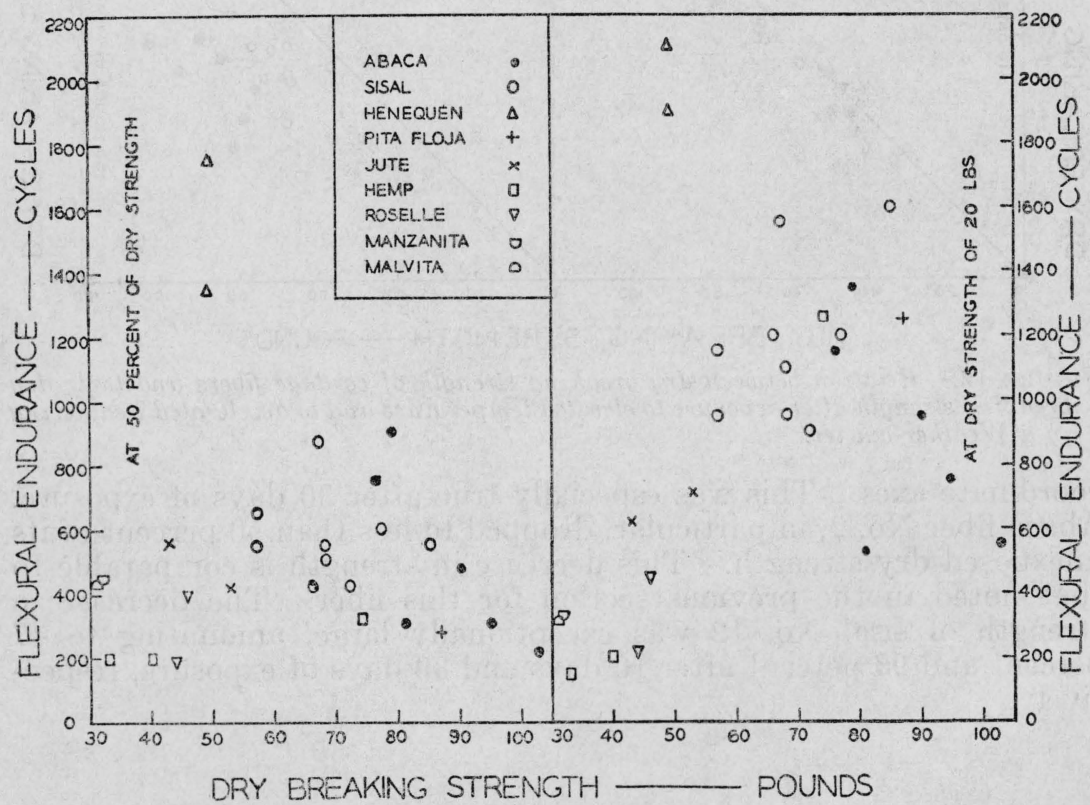

FIGU 15.-Relation between dry breaking strength of cordage fibers and their flexural endurance. 

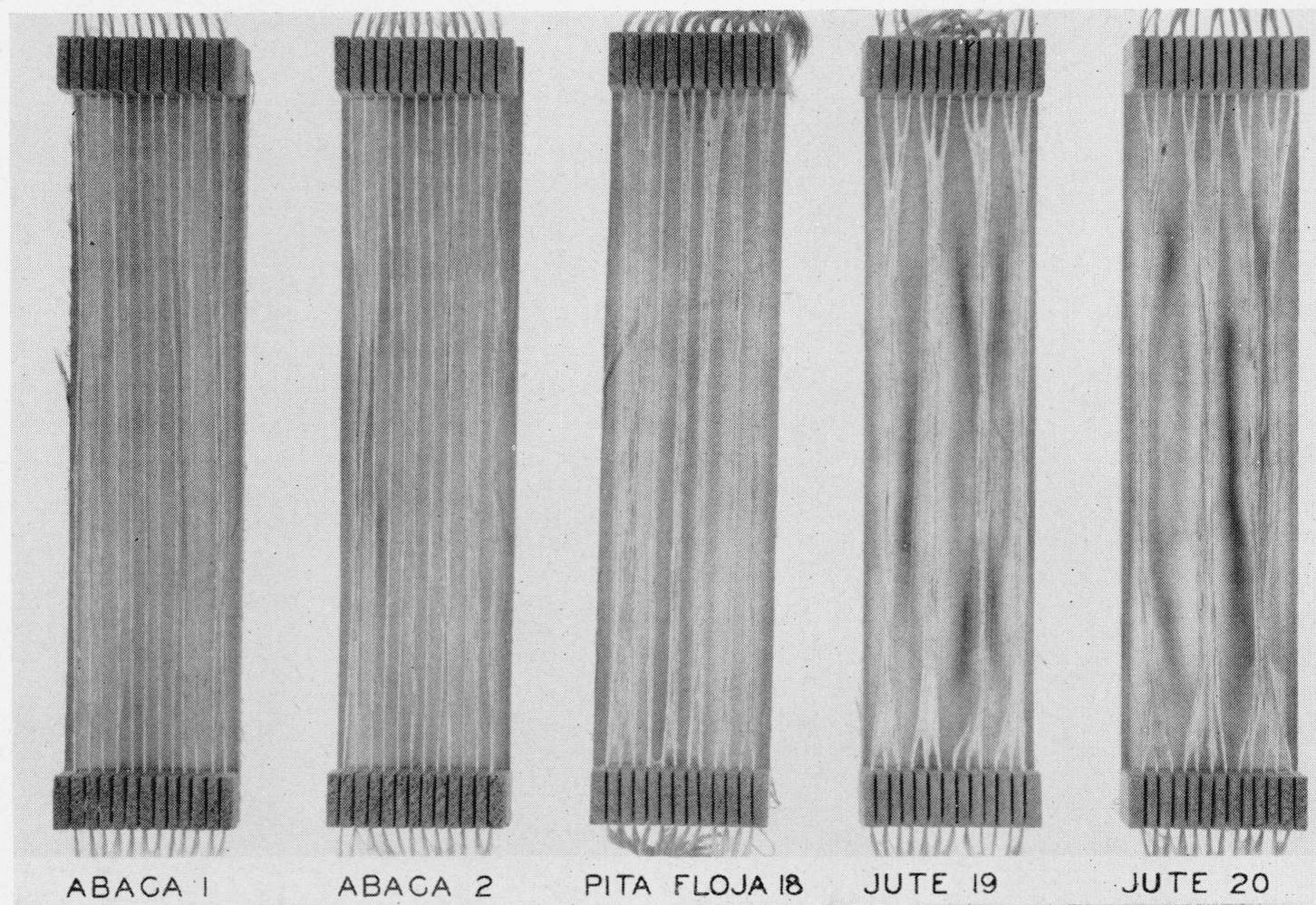

Figure 13.-Appearance of abaca, pita floja, and jute fibers after 183 hours' exposure in Weather-ometer. 

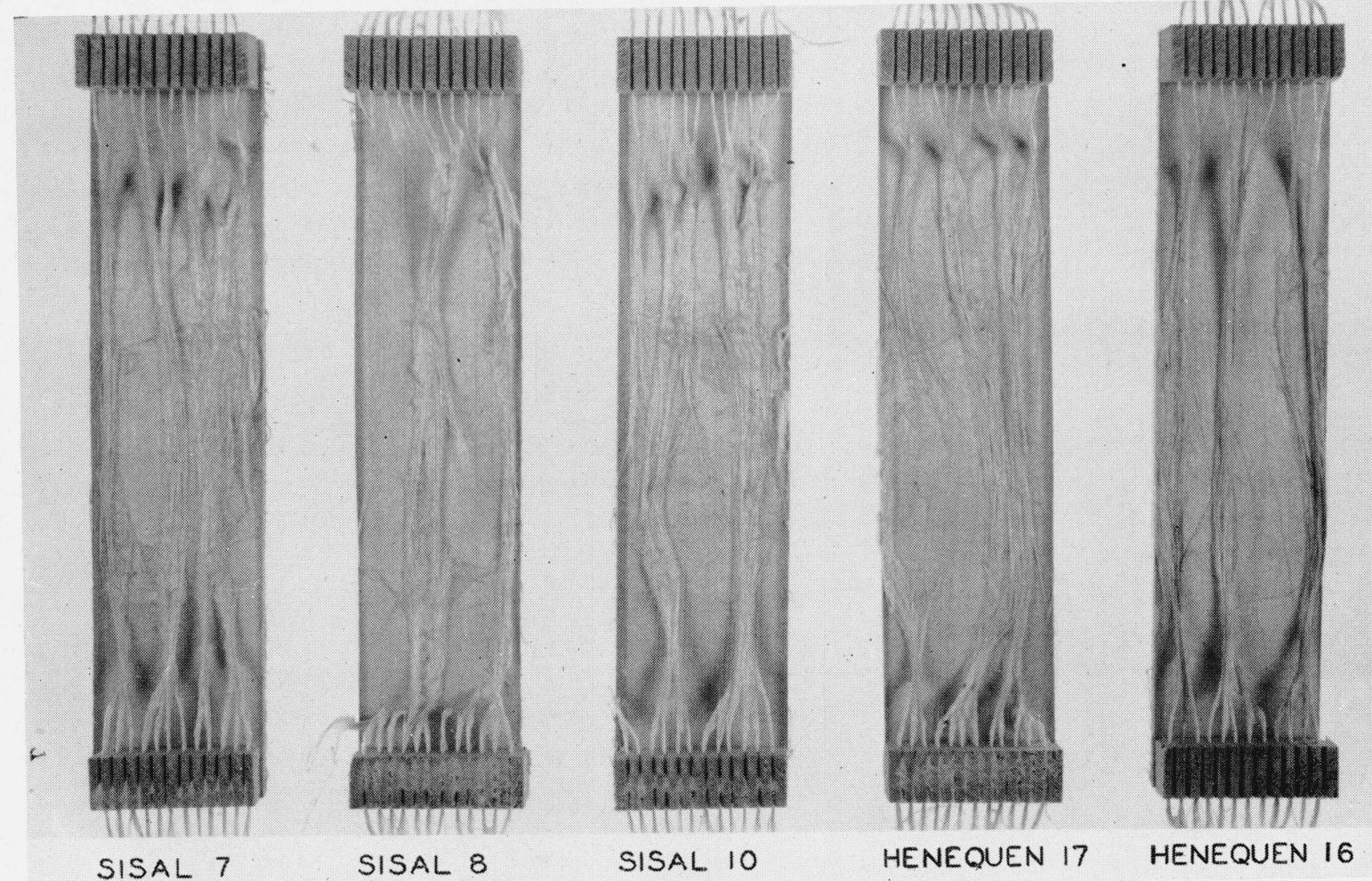

FIGURE 14.- Appearance of henequen and sisal fibers after 183 hours' exposure in Weather-ometer. 
dry breaking strength of the fibers. The plotted points show no definite correlation between the flexural endurance and dry strength. The flexural endurance of henequen was considerably greater than for the other fibers. Since the elongation of the henequen fiber was also considerably greater than for the other fibers, a correlation between flexural endurance and elongation is indicated. The flexural endurance is plotted in figure 16 against the dry elongation of the fibers. In general, the flexural endurance increased with the intrinsic elongation of fibers, relative freedom of movement of the structural units within the fibers. This result is in substantial agreement with the effect of relative freedom of movement of the fibers in a yarn, and of yarns in a fabric on the folding endurance of fabrics. ${ }^{3}$ Fibers having a high elongation, such as nylon, should greatly excel in flexural endurance any of the cordage fibers tested.

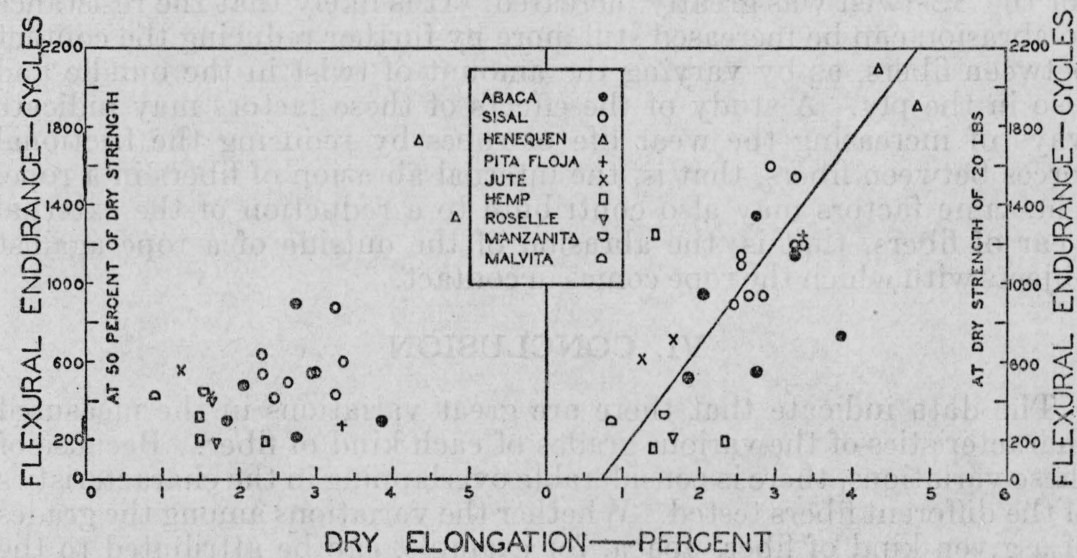

FIGURE 16.-Relation between dry elongation of cordage fibers and their flexural endurance.

\section{RESISTANCE TO ABRASION}

(a) S-TWIST IN THE BUNDLE AND IN THE PLY

The resistance to abrasion of the fibers for the SS-twist, that is, S-twist in the bundle of fibers and an S-twist in the ply of two bundles, varied over a great range. The results do not seem to correlate with any of the other fiber properties measured, except fineness of fiber. The resistance to abrasion of fibers 1 to 15 , inclusive, all of which are classed as hard fibers, is very much higher than that of fibers 16 to 27 , inclusive, all of which are classed as soft fibers. The fineness of fiber, expressed in feet per pound, of the hard fibers is very much smaller than for the soft fibers.

\section{(b) S-TWIST IN THE BUNDLE AND Z-TWIST IN THE PLY}

The resistance to abrasion of the fibers for the SZ-twist, that is, S-twist in the bundle of fibers and a Z-twist in the ply of two bundles, also varied over a great range. The results did not fall into two dis-

\footnotetext{
${ }^{3}$ Herbert F. Schiefer and Paul M. Boyland, Note on flexural fatigue of textiles, J. Research NBS 29, 69
} (1942) RP1485. 
tinct groups as for the SS-twist. The resistance to abrasion for some of the soft fibers exceeded that for some of the hard fibers. The results do not seem to correlate with any of the other characteristics measured.

The resistance to abrasion for the SZ-twist was very much greater in general than for the SS-twist. This large difference is attributed to the difference in contact between the fibers of the two bundles for the two twists. In the SS-twist the fibers of the two bundles are essentially parallel, and therefore make contact for a considerable distance along the length of a fiber. The opposite is true for the SZ-twist, in which the fibers of the two bundles cross each other. This difference in alignment of the fibers for the two twists is shown in figure 17. It is apparent that the resistance to abrasion depends upon the contact and frictional force between the fibers. It was found that if a small amount of lubricant was added to the fibers, the resistance to abrasion for the SS-twist was greatly increased. It is likely that the resistance to abrasion can be increased still more by further reducing the contact between fibers, as by varying the amount of twist in the bundle and also in the ply. A study of the effects of these factors may indicate ways of increasing the wear life of ropes by reducing the frictional forces between fibers, that is, the internal abrasion of fibers in a rope. The same factors may also contribute to a reduction of the external wear of fibers, that is, the abrasion of the outside of a rope against objects with which the rope comes in contact.

\section{CONCLUSION}

The data indicate that there are great variations in the measured characteristics of the various grades of each kind of fiber. Because of these variations, there is considerable overlapping in the characteristics of the different fibers tested. Whether the variations among the grades of a given kind of fiber, abaca, for example, can be attributed to the difference in grade cannot be stated with certainty, because some of these fibers had been stored for a number of years. The baling dates for the abaca fiber ranged for 1941 to 1936 , that is, 2 to 7 years before the fibers were tested. Abaca fiber No. 2, which was baled in 1941, was considerably stronger than those baled in 1936, namely, fibers $3,4,5$, and 6 . Although abaca had the highest strength of the fibers tested, several grades of sisal, pita floja, and sansevieria were stronger than some of the grades of abaca. The abaca fiber, which had the highest dry breaking strength, was the third weakest after 28 days of soaking in fresh water.

The henequen fibers had the highest elongation. Although their dry strength was only about half of that of the abaca, they had the highest flexural endurance. They were affected little by exposure to elevated temperature, but disintegrated completely upon exposure to light and intermittent spraying with water. Sisal also disintegrated in this test and the breaking strength of the remaining fibers was drastically reduced.

The resistance to abrasion was highest for henequen and sisal. Pita floja, which is one of the strongest fibers tested, was among the lowest in resistance to abrasion. The resistance to abrasion of the fibers tested was profoundly affected by the direction of twist in the ply 


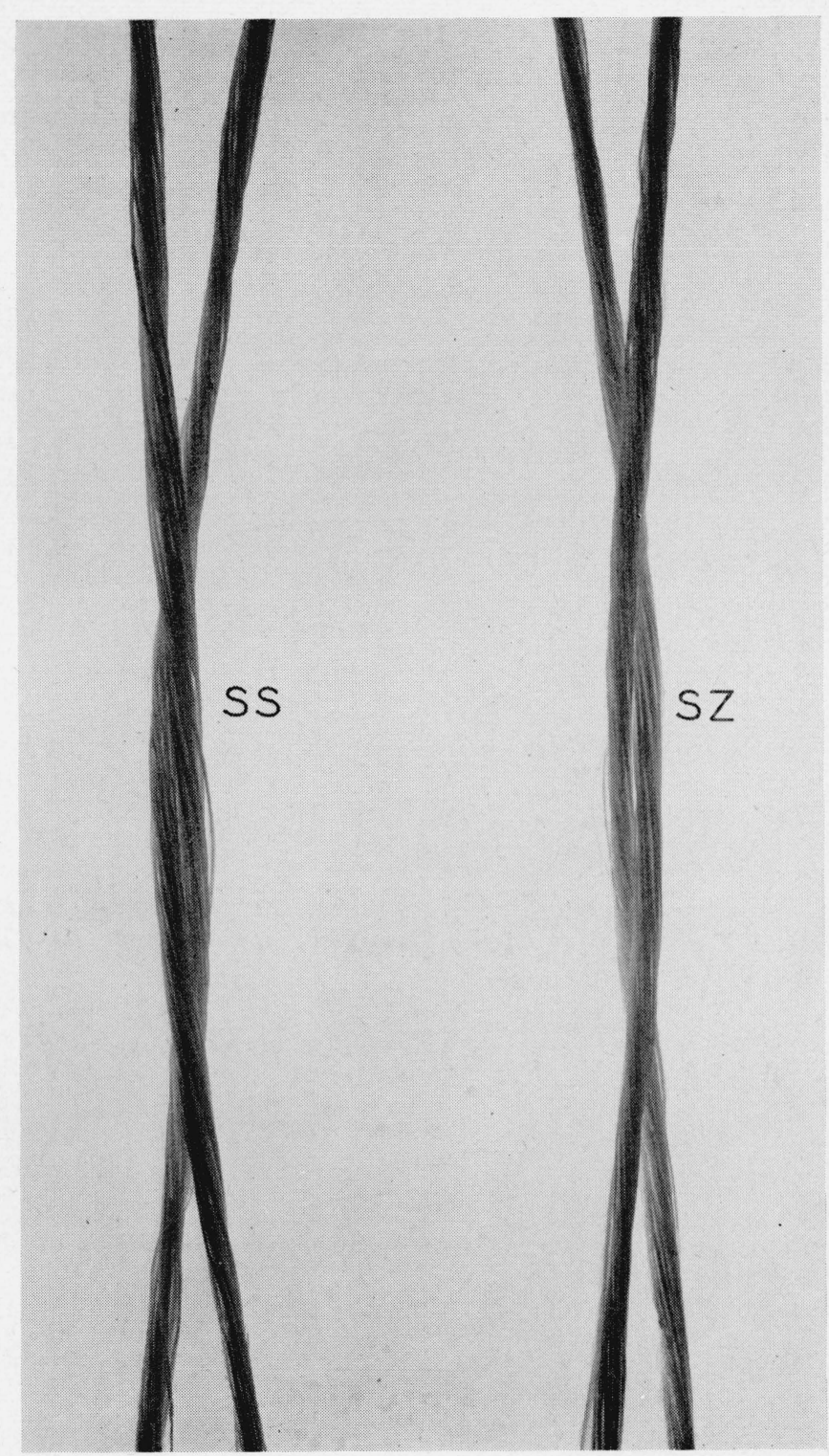

FIGURE 17.-Alinement of fibers for SS-twist and SZ-twist of the abrasion tests. 
relative to that in the bundle, and also by the addition of a small amount of lubricant.

Sansevieria had exceptionally good dry strength. Sufficient material was not available for making the other tests on sansevieria. Hemp and jute were very similar in all the characteristics measured.

The testing machines and methods described in this paper are thought to be suitable not only for a quick evaluation of the characteristics of new or experimental fibers, usually available only in small quantities, but also for a systematic and comprehensive investigation of the characteristics of all grades and kinds of cordage fibers. A correlation study of the results of tests of fibers with the results of tests of cordage and rope made from the same fibers might contribute materially to the production of more uniform and durable products, especially those suitable for specific uses requiring higb impact strength, high fiexural endurance, or high resistance to internal and external abrasion. Since the machines and methods are applicable for testing small quantities of fiber, such as from a single leaf, they should prove useful in the evaluation of agricultural experiments for growing improved cordage fibers or in the evaluation of chemical treatments and processing of the fibers.

The author expresses his appreciation to Betty J. Skrdla, Jean Persons, Dorothy Rundles, and Philip Miller for carefully preparing the large number of bundles of fibers and for making the numerous tests of the various characteristics of the fiber. The assistance of Gladys White in the preliminary experiments and in checking some of the computations and that of Josephine Blandford in the preparation of the graphs is gratefully acknowledged. Finally, the cooperation of the American Manufacturing Co., Boston Navy Yard, Hooven \& Allison Co., Plymouth Cordage Co., U. S. Department of Agriculture, Wall Rope Works, and Whitlock Cordage Co. in furnishing most of the fibers for the tests is appreciated.

Washington, June 23, 1944. 


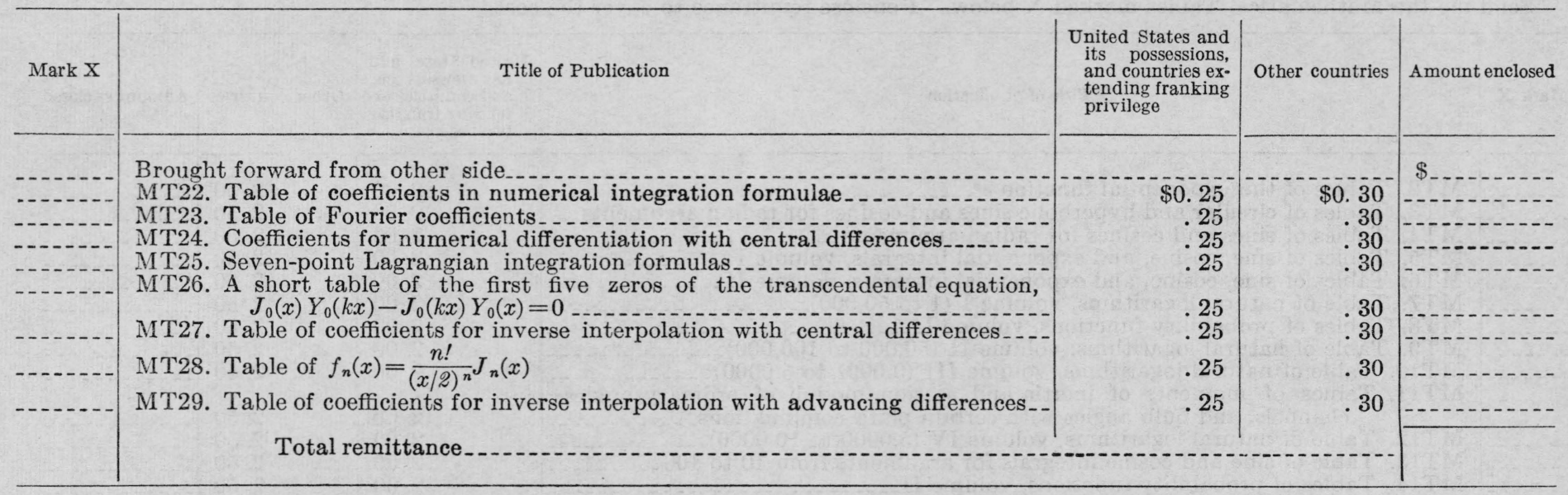

Remittance should be in form of post-office money order, or check, and made payable to the order of the "National Bureau of Standards" in United States currency

Send to

Number and Street

City, Zone, and State 


\section{NATIONAL BUREAU OF STANDARDS, WASHINGTON 25, D. C.}

Send me the Mathematical Tables marked X below. I enclose remittance to cover the cost.

\begin{tabular}{|c|c|c|c|c|}
\hline Mark X & Title of publication & $\begin{array}{l}\text { United States and } \\
\text { its possessions, } \\
\text { and countries ex- } \\
\text { tending franking } \\
\text { privilege }\end{array}$ & Other countries & Amount enclosed \\
\hline (1) & 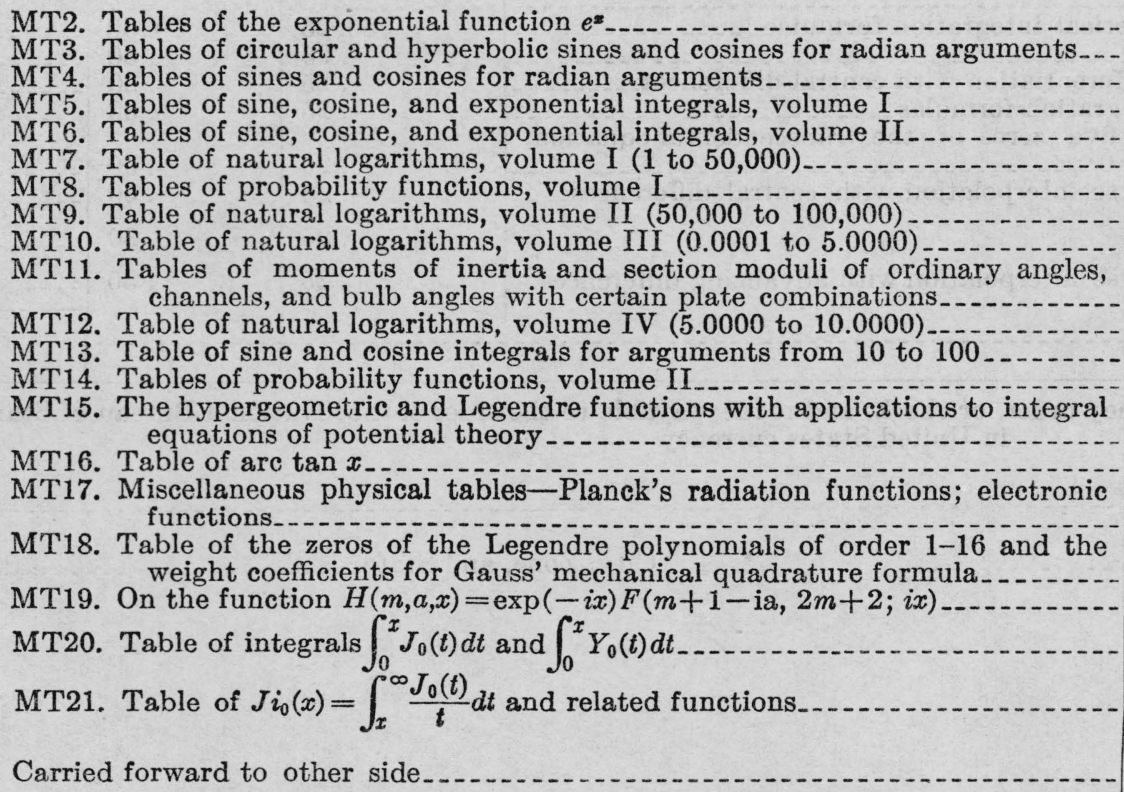 & $\begin{array}{r}\$ 2.00 \\
2.00 \\
2.00 \\
2.00 \\
2.00 \\
2.00 \\
2.00 \\
2.00 \\
2.00 \\
2.00 \\
2.00 \\
2.00 \\
2.00 \\
2.00 \\
2.00 \\
1.50 \\
\\
.25 \\
.25 \\
.25\end{array}$ & $\begin{array}{r}\$ 2.50 \\
2.50 \\
2.50 \\
2.50 \\
2.50 \\
2.50 \\
2.50 \\
2.50 \\
2.50 \\
2.50 \\
2.50 \\
2.50 \\
2.50 \\
2.50 \\
2.50 \\
1.75 \\
.30 \\
.30 \\
.30 \\
\\
.30\end{array}$ & 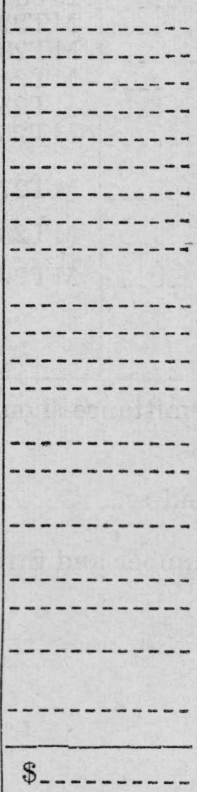 \\
\hline
\end{tabular}




\section{MATHEMATICAL TABLES}

Attention is invited to a series of publications prepared by the Project for the Computation of Mathematical Tables conducted by the Federal Works Agency, Work Projects Administration for the City of New York, under the sponsorship of the National Bureau of Standards. The tables which have been made available through the National Bureau of Standards are listed below. A list of other WPA tables obtainable, elsewhere will be sent by the Bureau on request.

There is included in this list a publication on the hypergeometric and Legendre functions (MT15), prepared by the Bureau.

MT1. Table of the First Ten Powers of the Intrgers From 1 to 1000: (1938) VIII +80 pages; heavy paper cover. Out of print.

MT2. TAbles of the Exponential Function $e^{x}$ : The ranges and intervals of the argument and the number of decimal places in the entries are given below:

$\begin{array}{lcc}\text { Range of } x & \text { Interval of } x & \text { Decimals given } \\ -2.5000 \text { to } 1.0000 & 0.0001 & 18 \\ 1.0000 \text { to } 2.5000 & .001 & 15 \\ 2.500 \text { to } 5.000 & .001 & 15 \\ 5.00 \text { to } 10.00 & .01 & 12\end{array}$

(1939) XV + 535 pages; bound in buckram, $\$ 2.00$.

MT3. Tablps op Circular and Hyperbolic Sines and Cosinfs por Radian Arguments: Contains 9 decimal place values of $\sin x, \cos x, \sinh x$, and $\cosh x$ for $x$ (in radians) ranging from 0 to 2 at intervals of 0.0001 . (1939) XVII +405 pages; bound in buckram, $\$ 2.00$.

MT4. Table: op oIngs and Cosinfs por Radian Arguments: Contains 8 decimal rlace values of sines and cosines for radian arguments ranging from 0 to 25 at intervals of 0.601 . (1940) XXIX +275 pages; bound in buckram, $\$ 2.00$.

MT5. Tarlfs op Sine, Cosine, and Exponential Integrals, Volume I: Values of these functions to 9 places of decimals from 0 to 2 at intervals of 0.0001 . (1940) XXVI +444 pages; bound in buckram, $\$ 2.00$.

MT6. Tablps of Sine, Cosine, and Expongntial Integrals, Volume ll: Values of these functions to 9,10 , or 11 significant figures from 0 to 10 at intervals of 0.001 with auxiliary tables. (1940) XXXVII + 225 pages; bound in buckram, $\$ 2.00$.

MT7. Table op Natural Logarithms, Volume I: Logarithms of the integers from 1 to 50,000 to 16 places of decimals. (1941) XVIII + 501 pages; bound in buckram, $\$ 2.00$.

MT8. Tablps op Probannity Functions, Volume 1: Values of these functions to 15 places of decimals from 0 to 1 at intervals of 0.0001 and from 1 to 5.6 at intervals of 0.001 . (1941) XXVIII + 302 pages; bound in buckram, $\$ 2.00$.

MT9. Table of Natural Logarithms, Volume II: Logarithms of the integers from $50,0 \mathrm{co}$ to 100,000 to 16 places of decimals. (1941) XVIII + 501 pages; bound in buckram. $\$ 2.00$.

MT10. Table of Natural Logarithms, Volume 111 : Logarithms of the decimal numbers from 0.0001 to 5.0000 , to 16 places of decimals. (1941) XVIII +501 pages; bound in buckram, $\$ 2.00$.

MT11. Tables op the Moments op Inertia and Section Modul op Ordinary Angles. Chano nels, and Bulb Angles with Certain Plate Combinationg: (1941) XIII + 197 pages; bound in green cloth. $\$ 2.00$.

MT12. Table of Natural Logarithms, Volume IV: Logarithms of the decimal numbers from 5.0000 to 10.0000 , to 16 places of decimals. (1941) XXII + 506 pages; bound in buckram, $\$ 2.00$.

MT13. T Able of Sine and Cosine INtegrats por Arguments prom 10 to 100: (1942) XXXI1 + 185 pages; bound in buckran, $\$ 2.00$.

MT14. Tables of Probarility Functions, Volume II: Values of these functions to 15 places of decimals from 0 to 1 at intervals of 0.0001 and from 1 to 7.8 at intervals of 0.001 . (1942) XXI +344 pages; bound in buckram, $\$ 2.00$.

MT15. The Hypergeometruc and Legendre Functions Wrth Applications to Intrgral Equa. tions or Potential Theory. By Chester Snow, National Bureau of Standards. Reproduced from original handwritten manuscript. (1942) VII +319 pages, bound in heavy paper cover, $\$ 2.00$.

MT16. TABLr or ARC $T_{\text {AN }} x$ : Tahle of inverse tangents for positive values of the angle in radians. Second central differences are included for all entries. $x=[0(.001) 7(.01) 50(.1) 300(1) 2,000(10)$ 10,$000 ; 12 D \rrbracket(1942) \mathrm{XXV}+169$ pages; bound in buckram, $\$ 2.00$. 


\section{[Continued from p. 3 of cover]}

MT17. Mrscerlangous Physicat Tables: Plancr`s Radiation Functions (Originally published in the Journal of the Optical Society of America, February 1940); and Electronic Functions. (1941) VII + 58 pages; bound in buckram, $\$ 1.50$.

MT18. Table or the Zrosos op the Legrndre Polynomials of Order 1-16 and the Weight Coeprictents for Gauss' Mrchanical Quadrature Formula. (Reprinted from Bul. Amer. Mathematical Society, October 1942.) 5 pages, with cover, 25 cents.

MT19. ON the Function $H(m, a, x)=\exp (-i x) F(m+1-i a, 2 m+2 ; i x)$; with tahle of the confluent hypergeometric function and its first derivative. (Reprinted from J. Math. Phys., December 1942.) 20 pages, with cover, 25 cents.

MT20. Table or Intrgrals $\int_{0}^{x} J_{0}(t) d t$ and $\int_{0}^{x} Y_{0}(t) d t$. (Reprinted from J. Math. Phys., May 1943.) 12 pages, with cover, 25 cents.

MT21. Table of Jio $(x)=\int_{x}^{\infty} \frac{I_{0}(t)}{t} d t$ ANd Related Functions. (Reprinted from J. Math. Phys., June 1943.) 7 pages, with cover, 25 cents.

MT22. Tablr of Coepricients in Numerical Intrgration Formulae. (Reprinted from J. Math. Phys., June 1943.) 2 pages, with cover, 25 cents.

MT23. Table or Fourier Corpricients. (Reprinted from J. Math. Phys., Sept. 1943.) 11 pages, with cover, 25 cents.

MT24. Coeppicients for Numerical Dipperentiation With Central Difperences. (Reprinted from J. Math. Phys., Sept. 1943.) 21 pages, with cover, 25 cents.

MT25. Seven-Point Lagrangian Intrgration Formulas. (Reprinted from J. Math. Phys. Dec. 19+3.) 4 pages, with cover, 25 cents.

MT26. A Short Tarle op the First Five Zeros of the Transcendental Equation. $J_{j}(x) Y_{0}(k x)-J_{0}(k x) Y_{0}(x)=0$. (Reprinted from J. Math. Phys., Dec. 1943.) 2 pages, with cover, 25 cents.

MT27. Table of Coepricients por Inverse Interpolation with Central Dipperences. (Reo printed from J. Math. Phys., Dec. 1943.) 15 pages, with cover, 25 cents.

MT28. TABLR o: $f_{n}(x)=\frac{n !}{(x / 2)^{n}} J_{n}(x)$ (Reprinted from J. Math. Phys, Feb. 1944) 16 pages, with cover, 25 cents.

MT29. Tamle of Coeppictents for Inverse Interpolation with Advancing Difperences. (Reprinted from J. Math. Phys., May 1944.) 28 pages, with cover, 25 cents.

Payment is required in advance. Make remittance payable to the "National Bureau of Standards" and send with order, using the blank form facing page 3 of the cover.

A mailing list is maintained for those who desire to receive announcements regarding new tables as they become available. 